\title{
Positional Accuracy Assessment of Digital Orthophoto Based on UAV Images: An Experience on an Archaeological Area
}

\author{
Saadet Armağan Güleç Korumaz ${ }^{1, *}$ and Ferruh Yıldız ${ }^{2}$ \\ 1 Department of Architecture, Faculty of Architecture and Design, Konya Technical University, Akademi \\ Mahallesi Yeni İstanbul Cad. No: 235/1, Selçuklu, 42250 Konya, Turkey \\ 2 Department of Geomatica Engineering, Faculty of Engineering and Natural Science, Konya Technical \\ University, Ardıçlı Mahallesi Rauf Orbay Cad., Selçuklu, 42250 Konya, Turkey; fyildiz@ktun.edu.tr \\ * Correspondence: sagkorumaz@ktun.edu.tr; Tel.: +90-530-402-4141
}

check for updates

Citation: Korumaz, S.A.G.; Yıldız, F. Positional Accuracy Assessment of Digital Orthophoto Based on UAV Images: An Experience on an Archaeological Area. Heritage 2021, 4, 1304-1327. https://doi.org/10.3390/ heritage 4030071

Academic Editor: Geert Verhoeven

Received: 30 May 2021

Accepted: 7 July 2021

Published: 16 July 2021

Publisher's Note: MDPI stays neutral with regard to jurisdictional claims in published maps and institutional affiliations.

Copyright: (c) 2021 by the authors. Licensee MDPI, Basel, Switzerland. This article is an open access article distributed under the terms and conditions of the Creative Commons Attribution (CC BY) license (https:// creativecommons.org/licenses/by/ $4.0 /)$.

\begin{abstract}
Rapid development in UAV (unmanned aerial vehicle) photogrammetry made it preferable in many applications including cultural heritage documentation. Usability, quickness and accuracy of digital images have grabbed also the attention of archaeologists. Especially orthoimages by UAVs have become considerably significant in the field of archaeological heritage documentation since they are fast and accurate images of the object with high detailed information. However their accuracy and quality are the most important features of these images for archaeological documentation. The aim of this paper is to evaluate horizontal and vertical accuracy of an orthophoto taken by a fixed-wing UAV in an archaeological area. The evaluation is made according to ASPRS (American Society for Photogrammetry and Remote Sensing) Accuracy Standards for Digital Geospatial Data. The archaeological area, the name of which is Kubad Abad Palace in Beyşehir Province in Konya, is the only Anatolian Seljuk Palace structure that has survived to the present day. The study describes the orthophoto generation process and positional accuracy evaluation results within the frame of the importance of accuracy for archaeological documentation.
\end{abstract}

Keywords: orthophoto; orthophoto accuracy; archaeological heritage; ASPRS

\section{Introduction}

With the developments in image capturing and image processing, UAVs have become an alternative for cultural heritage documentation and have started to be used in diverse heritage projects. In a cultural heritage area, UAV applications are mainly focused on aerial documentation [1], observation, monitoring [2], mapping [3], 3D modeling [4] as well as producing digital orthophoto, digital elevation model (DEM) and digital surface models (DSMs) [5].

In archaeological projects, there is always a need for accurate documentation of the objects. Even though fast, accurate, cheap modeling and visualization of archaeological areas are a demand, there are some situations making this demand difficult. The complexity of archaeological areas, their geometric and radiometric features and their conceptual interpretation are among these situations.

Compared with traditional documentation techniques in archaeological areas, UAVs have brought stunning innovation and ease to get aerial images of the total area. The information obtained from aerial or satellite images provides an overview of the area, which is fundamental for the interpretation of archaeological structures. In fact, the images obtained by metric aerial cameras (film and digital) or by high-resolution satellite sensors have been used in archaeology for a long time [6]. It should be pointed out that such images have some limitations. Many times geometric resolution of these images is inadequate for detailed studies. Another limitation is related to the periods of acquisition which do not always correspond to given particularly useful data for the purposes of the archaeological work and ultimately to the expense [7]. Up to today, diverse kinds of 
manned and unmanned platforms have been used in archaeology in order to get aerial images. Among them, there are mats, poles, booms, towers as well as kites, balloons, blimps and helikites [8]. Whittlesey reported on the use of a tethered balloon for archaeological documentation for the first time in 1970, which he had actually started in 1967 [9]. Even though airborne photogrammetric surveys are used for archaeological area documentation, in some cases, they can be unfeasible because of the limited site extent, the large scale required and the expected low flight height, speed of the aircraft and the relatively high cost of the technique [10].

With the development of light unmanned aerial vehicles (UAVs), the number of studies has increased considerably in the last years. In literature, much diverse research and studies about the use of UAVs for archaeological purposes can be found. Some of them can be mentioned as generating color orthophotos, DEMs, 3D models and thermal images for observation of archaeological areas [4,11], documentation of archaeological excavations [12,13] and several ancient sites [14], burial mounds [15], modeling and recording of archaeological heritage [16,17], archaeological remains documentation [18] and 3D mapping [3].

In this study, a practical application of a UAV system was used to check the accuracy of an orthophoto for large-scale mapping of an archaeological area in Beyşehir town of Konya city.

\section{Orthophoto Accuracy for Archaeology}

Technological progress has pushed a high demand for geographic data. Both users and governments have started to require good-quality data. When it is considered to be useful for geometric information, accuracy should be required for all its components (i.e., spatial, temporal, topological and thematic). What makes UAV use appealing for archaeology and other fields is its high spatial and temporal resolution [19].

Orthophotos are images that have all distortions due to camera obliquity and terrain relief removed, and they combine the image characteristics of a photograph with the geometric qualities of a map [20]. The science of archaeology has preferred to use orthophotos since they are a detailed pictorial view of the earth's surface and topographic information. Archaeologists prefer to use an orthophoto since:

-It is flexible and allows map information that can be shared easily;

-It contains everything from the original photograph;

-It can be produced in a short time;

-It provides up-to-date information;

-It has the geometric accuracy of a map;

-It has all the visual characteristics of an image [21].

As an orthophoto shows an image of objects in their true orthographic positions, they are geometrically equivalent to conventional line and symbol planimetric maps. The major difference between an orthophoto and a map is that an orthophoto is composed of images of features, whereas maps utilize lines and symbols plotted to scale to depict features $[22,23]$.

In a cartographic product, it is important to assess the spatial, spectral, radiometric and temporal resolution of the product. Because of this, it is essential to know the objectives of a project in order to decide the platforms, tools and sensors to use. This is required also to assess the quality of all its components, including spatial resolution [19].

One of the most important quality features of cartographic products is positional accuracy. Positional quality is essential for generation of cartographic production. All NMAs (National Map Accuracy Standards) use statistical methods to control it. Spatial quality can be assessed using several tests or standards such as the NMAs, STANAG or NSSDA [24-26]. STANAG defines different accuracy ratings for absolute geometric accuracy. Each rate is identified by a letter from A to E, and A is considered the best accuracy rate. For each rate, it defines the maximum differences between any two welldefined points in map units [26]. NMAS sets a compliance accuracy value while the 
NSSDA (National Standard for Spatial Data Accuracy) uses root mean error (RMSE) to estimate positional accuracy [27]. RMSE is the square root of the average of a set of squared differences between data set coordinate values and coordinate values from an independent source of higher accuracy [27]. The spatial accuracy of a UAV orthophoto is mostly reported using the root mean square error [RMSE] [28].

The evaluation of accuracy and quality control are significant for digital orthophoto production. Not all orthophotos are generated at the same level, and thus their accuracy and quality change depending on the data used in the process and generation procedure.

An orthophoto accuracy is also influenced by many factors such as:

-Used methodology and workflow;

-Characteristics of used equipment;

-Quality of camera and calibration parameters;

-Flight height;

-Quality and size of a charged coupled device (CCD) used in the digital camera CCD array;

-Amount of imagery overlap;

-Quality of parallax determination or photo measurements;

-Quality of the GNSS signal;

-Quality, density and placement of ground control points;

-Quality of the aerial triangulation solution;

-Capability of the processing software to handle GNSS drift and shift;

-Capability of the processing software to handle camera self-calibration;

-Digital terrain model used for the production of orthoimagery;

-Resolution of the digital images;

-Fly height and number and placement of ground control points [21,27,29-33].

These factors can vary for each project. For this reason, existing accuracy measures based on map scale, ground sample distance (GSD) and scanning resolution no longer apply to current geospatial mapping practices.

Positional accuracy is the accuracy of the position of features, including horizontal and vertical positions, with respect to horizontal and vertical data. Positional accuracy is a product of the entire drone system (aircraft, sensors, operation and processing software), not any single component [31].

Positional accuracy of digital orthoimagery, which is independent of GSD, map scale or contour interval, depends on:

-Digital elevation data accuracy;

-Aerial triangulation accuracy;

-Ground control points' accuracy;

-Required number and spatial distribution of check points based on project area;

-The camera's inherent potential accuracy;

-The stability of the flight;

-The quality of the global navigation satellite system (GNSS) data;

-The quality of the inertial system (if the drone uses INS/IMU);

-The quality of the DEM used to make the orthophoto;

-The type and quality of processing of the raw imagery into an orthophoto;

-The number and quality of ground control points [31].

Each factor contributes some error to the ultimate positional accuracy of the final product. The sum of all errors determines the measurable positional accuracy [33].

The positional accuracy is usually determined for both horizontal and vertical coordinates. Horizontal positional accuracy is an estimate of accuracy of the horizontal positions of the spatial objects that can be measured in terms of latitude and longitude or local easting and northing coordinates [34]. Meanwhile, vertical positional accuracy refers to the uncertainty with which the vertical coordinates (ellipsoidal height/geocentric radius) of spatial objects can be measured. In general, the positional accuracy of orthophoto refers to the accuracy at which the position coordinates (latitude, longitude and ellipsoidal height) 
of the spatial objects that are well recognized in the orthophoto are estimated in reference to their corresponding ground-truth coordinates acquired at the same locations using an independent ground-based in-situ measurement such as GNSS observations [35].

There have been several studies done in the past in order to evaluate the accuracy of an orthophoto. Uysal et al. [17] obtained $0.062 \mathrm{~m}$ overall vertical accuracy from an altitude of $60 \mathrm{~m}$ [21]. Another study about quality assessment of UAV orthophotos was done by Mesas-Carrascosa et al. [19] by obtaining images with a vertically mounted digital camera. The orthophotos were assessed with various spatial quality tests used by national mapping agencies (NMAs) [19]. Udin and Ahmad (2014) conducted an assessment of photogrammetric mapping accuracy based on variation flying altitude using UAVs. Their objective was to determine the accuracy of the photogrammetric output, and they evaluated planimetry and vertical accuracy using RMSE depending on fly height [36]. Julge and Ellmann (2015) conducted an evaluation of the accuracy of orthophotos and 3D models from UAV photogrammetry. They evaluated the quality and accuracy of the products by comparing control measurements made with GNSS measurements on the ground, as well as high-resolution airborne laser scanning data and other available orthophotos. The results of vertical and planar comparison statistics were used to evaluate the accuracy of UAV data [30]. Another study by Sai et al. (2019) carried out a geometric accuracy assessment of orthophoto production from UAV aerial images. In their study, they made an investigation on geometric accuracy of the produced orthophotomosaic according to the ASPR standards [22]. Since acquisition of accurate spatial data from traditional data compilation techniques is expensive, Greenfeld (2001) used digital orthophoto quadrangles (DOQs) for establishing digital parcel coverages and to evaluate their accuracy [27]. GPS data are also used for checking the positional accuracy in large-scale mapping. Sisay et al. [37] used in-situ GPS data to approve the accuracy of horizontal coordinates and orientation of linear features of an orthophoto and line map of Bahir Dar city [37].

In this study, positional accuracy was checked according to ASPRS Standards, and the results were evaluated.

\section{Kubad Abad Palace as Case Study}

Kubad Abad Palace is a complex located on latitude $37^{\circ} 40^{\prime} 25.19^{\prime \prime} \mathrm{N}$ and longitude $31^{\circ} 24^{\prime} 15.59^{\prime \prime}$ E. The palace was recognized by the famous Seljuk historian Ibn Bibi. It was constructed upon the order of Alaâddin Keykubad I (1120-1236), and it was established as the summer residence of Sultan in the Anatolian Seljuk period and is the only Seljuk palace surviving today. The palace lies in the south-west of Lake Beyşehir, in south-west Central Anatolia in Turkey, just over $100 \mathrm{~km}$ west of the Seljuk capital in Konya and located $3 \mathrm{~km}$ north of the town of Gölkaya (Figures 1 and 2). The location of the palace was found by the Konya Museum Director Zeki Oral in 1949, after references about the location. The first excavations started in 1965-1966 by Katharina Ottodorn and in 1967 by Mehmet Önder. From 1980, the excavations were continued by a team of archaeologists under the direction of Prof. Rüçhan Arık. 


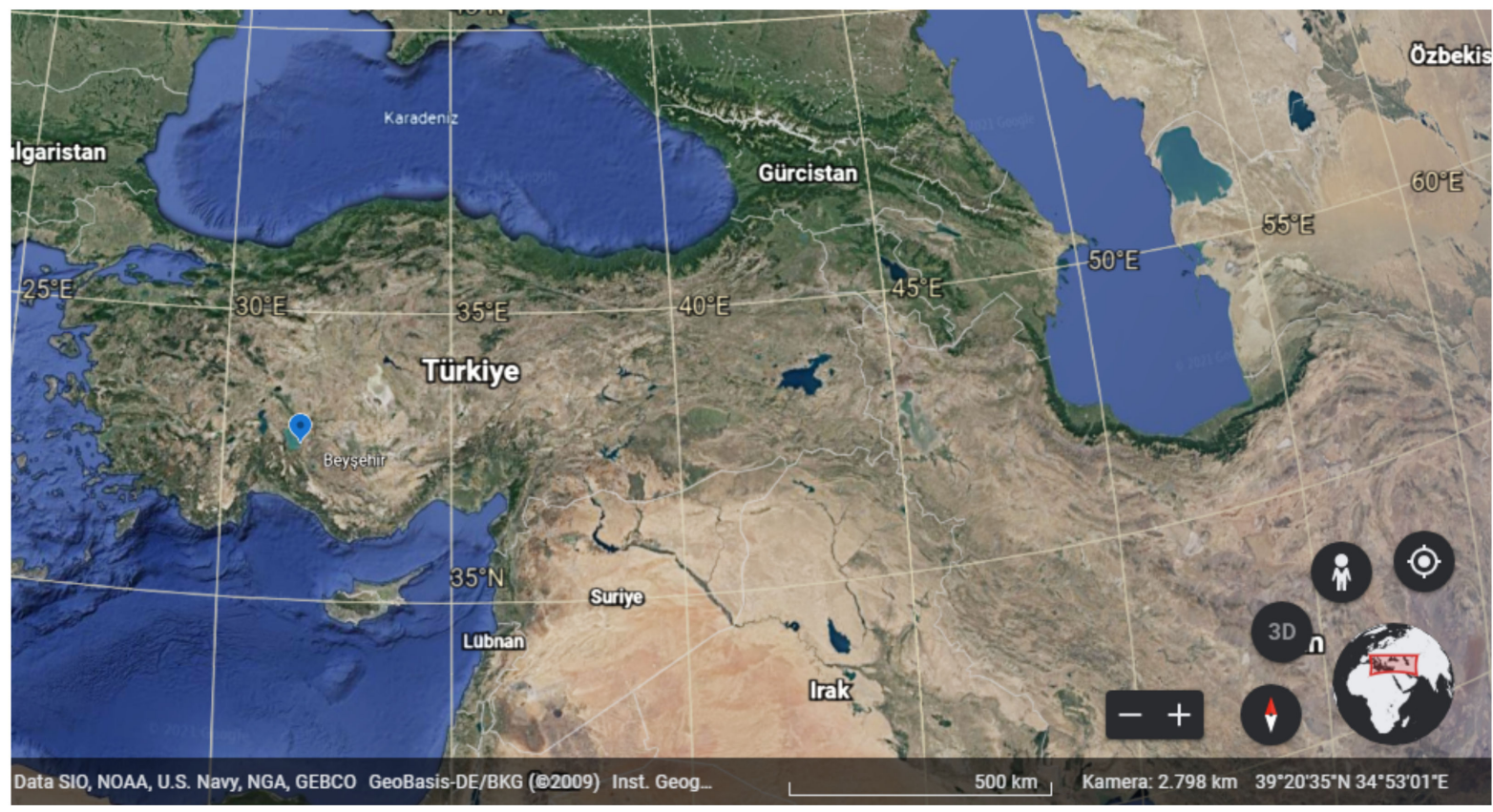

Figure 1. Beyşehir in Google Earth.

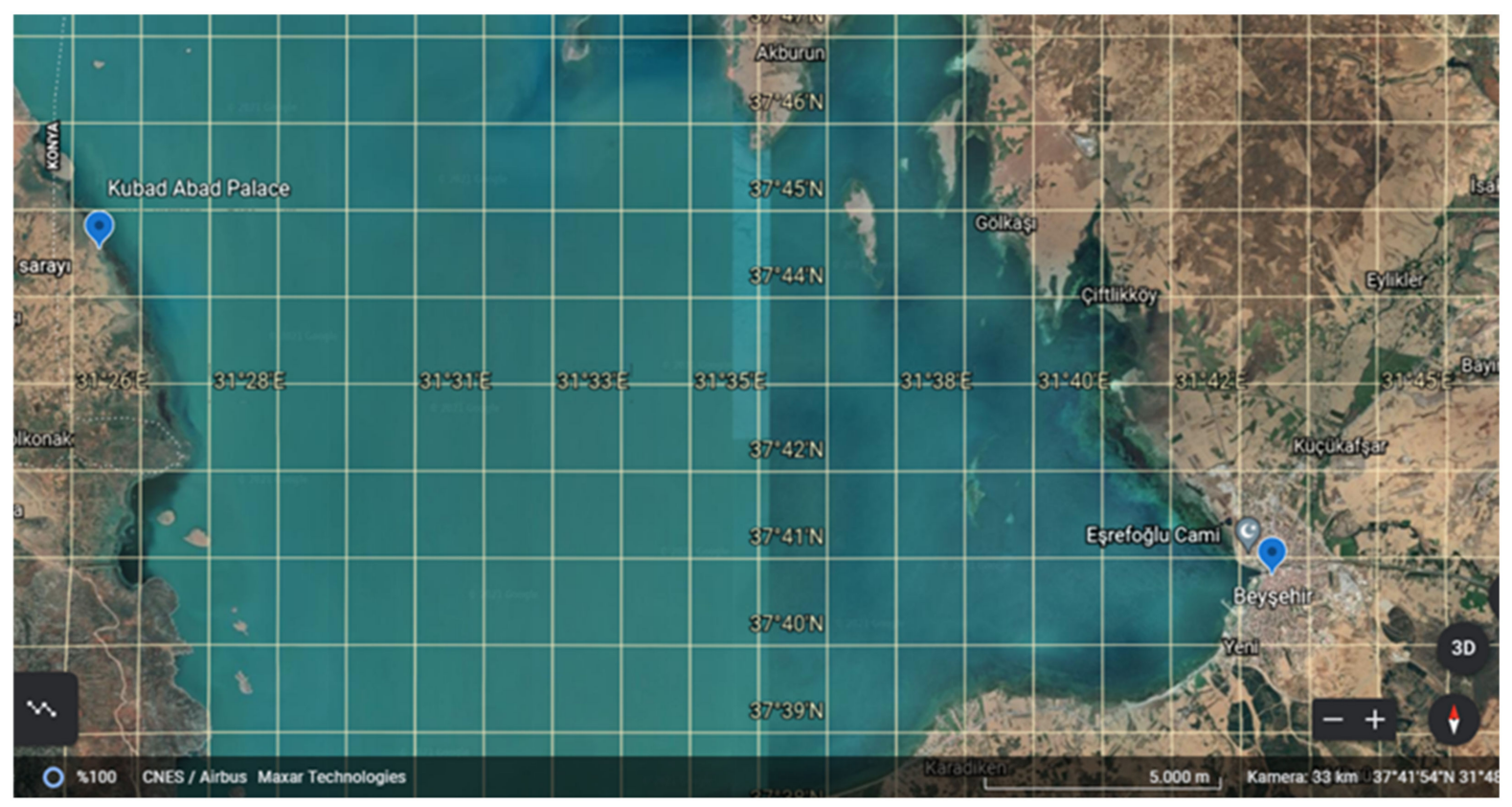

Figure 2. Location of the palace in Beyşehir and Beyşehir Lake.

The palace consists of various structures. It mainly consists of the Great Palace on the north side of the site and the Small Palace on the south of it, a boat house on the shore of the lake and small pavilions surrounding it, the walls of an inner courtyard and other ruined structure the functions of which have not been known yet (Figure 3). The Great Palace in size of $50 \mathrm{~m} \times 35 \mathrm{~m}$ is the largest building of the complex and consists of three main sections: a palace building, a courtyard and a terrace extending to the lake (Figure 4). The Small Palace also has a similar plan with thicker and more regular walls (Figure 5). Both buildings have a plan of large and small rooms on either side of an axis determined by an iwan once used as the throne room and the forecourt. The structures were constructed with rubble stone [38,39] (Figure 6). 


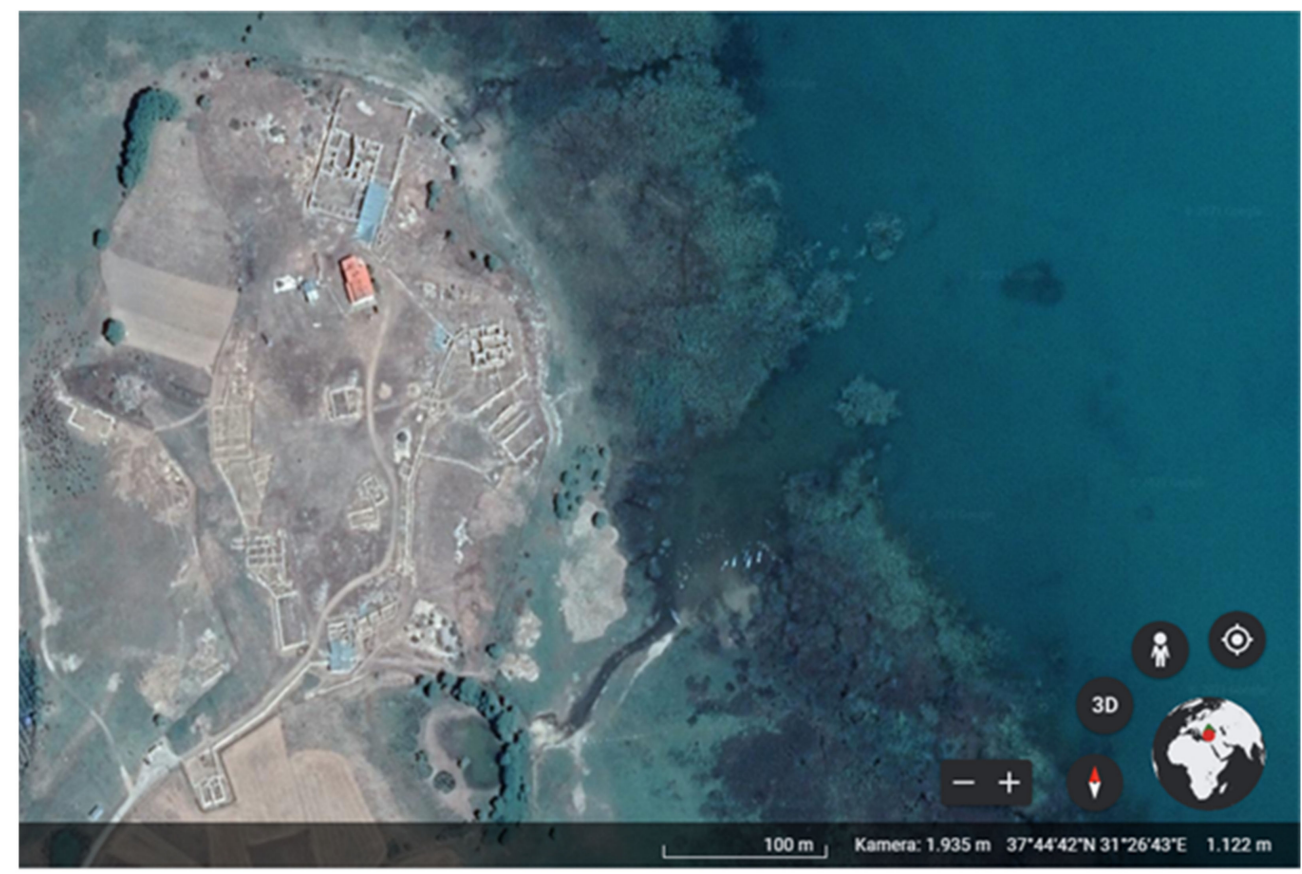

Figure 3. Kubad Abad Palace complex on Google Earth.

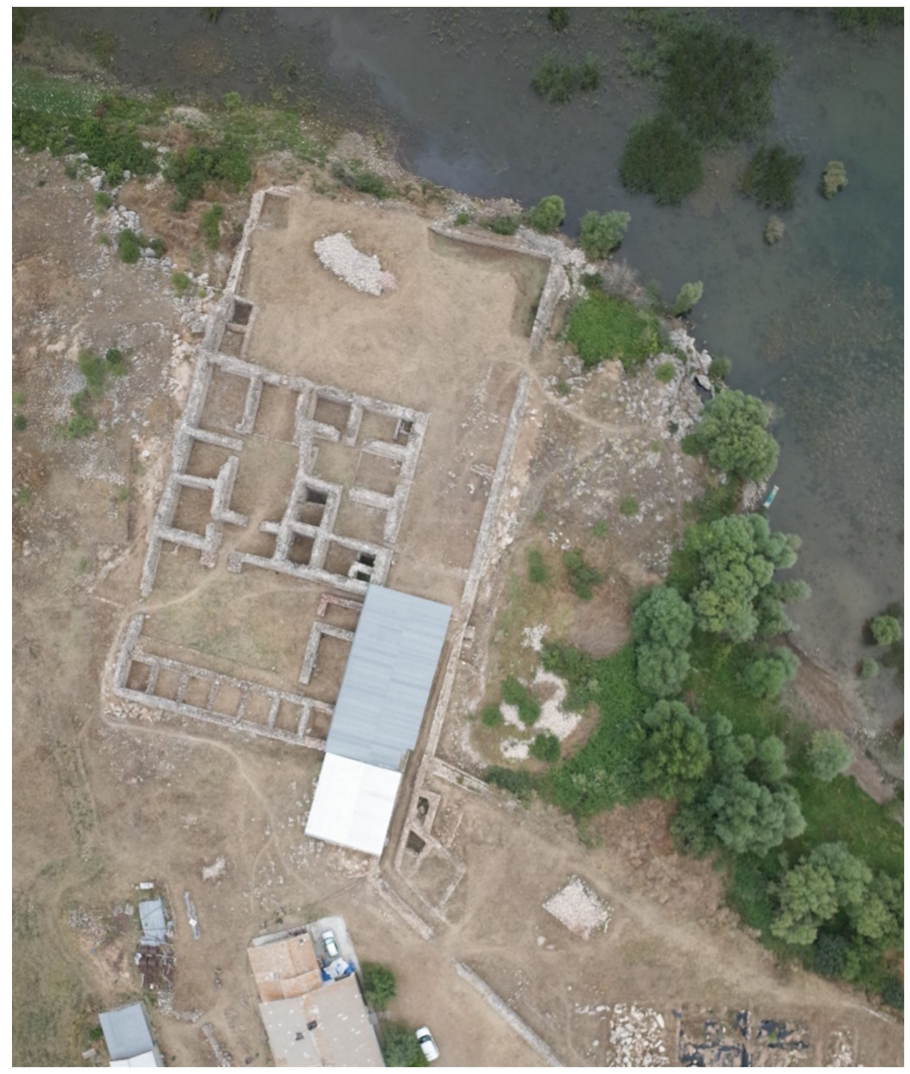

Figure 4. The Great Palace (detail from orthophoto).

Besides the structure, the palace was very famous for its tiles decorating the walls of the structure. Most of these tiles are in the shape of a star or a square, mostly with the traditional color turquoise and in the dimension of $20 \times 24 \mathrm{~cm}$. They are decorated with figurative motifs in luster or underglaze techniques. The influence of Central Asian traditions is felt in decoration compositions. Typical tiles are white, eight-pointed stars 
and have delicate figural paintings of humans and animals, including some of the best in Anatolian Seljuk representational art. Painted with underglaze in turquoise, green, purple and blue, these figural tiles are set on a background of cruciform-shaped turquoise tiles with arabesque motifs in black [38] (Figure 7).

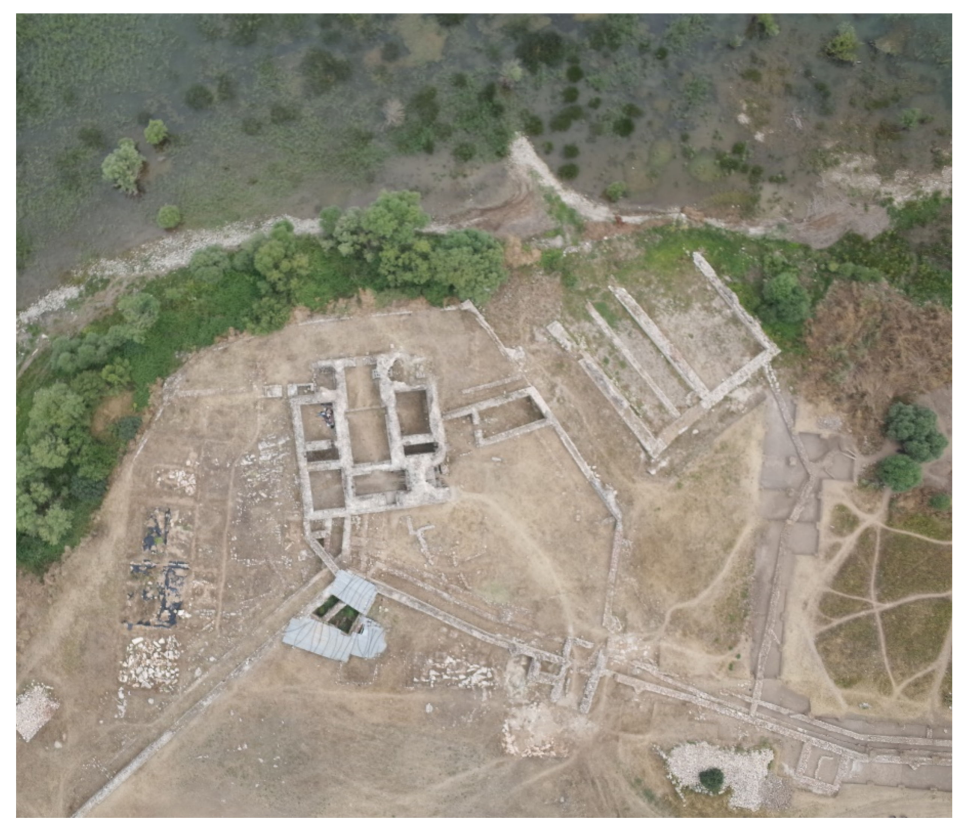

Figure 5. The Small Palace (detail from orthophoto).

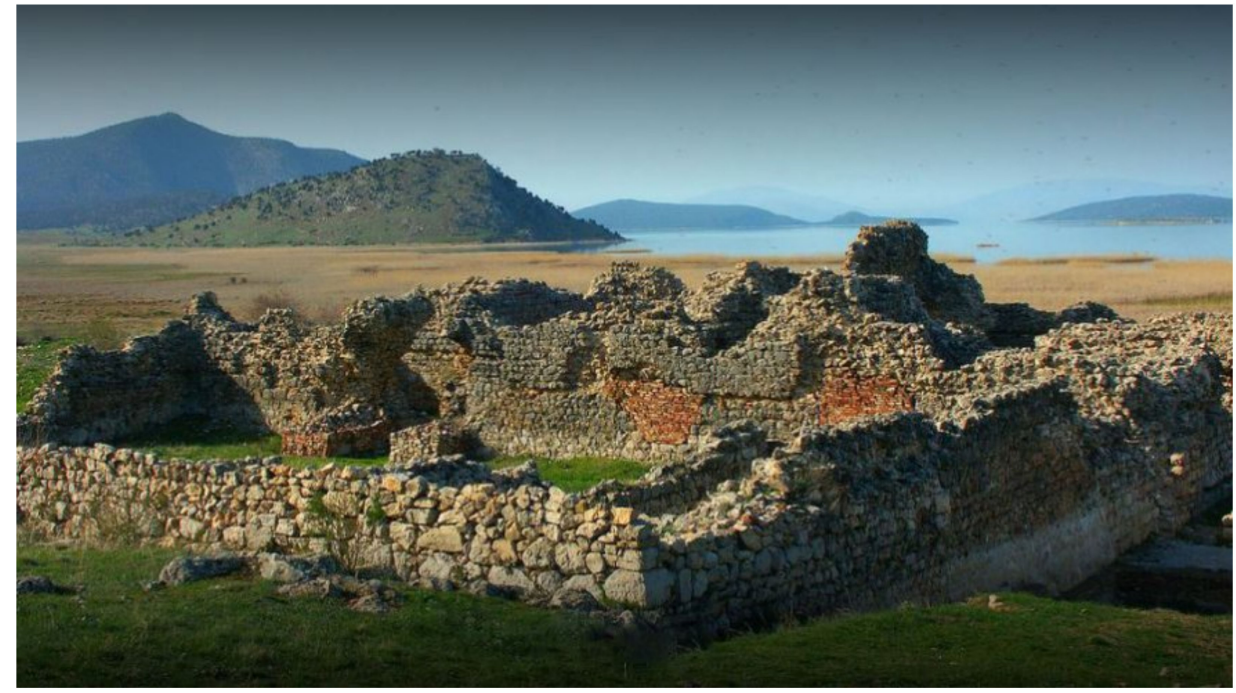

Figure 6. A general view of the walls today [40].
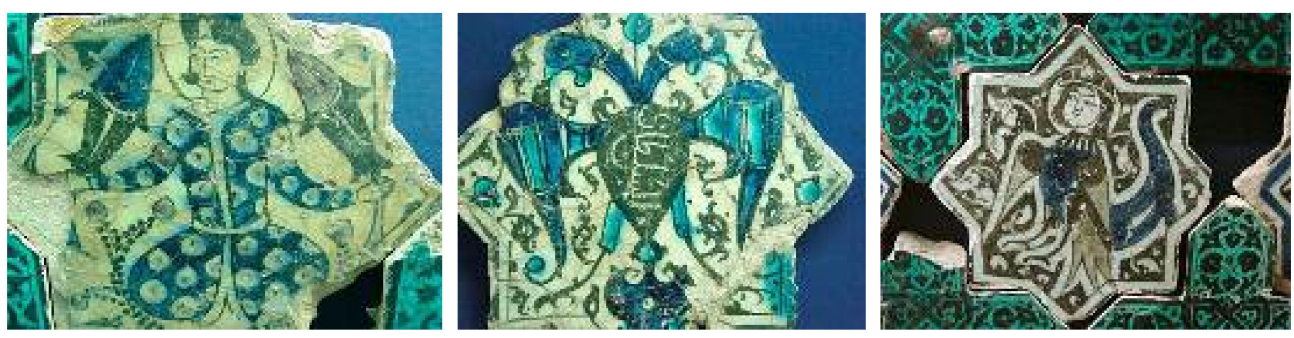

Figure 7. Some tiles from Kubad Abad Palace excavations, in Konya Karatay Museum. 


\section{Materials and Methods}

\subsection{Methodology}

Typical image-based aerial surveying with UAVs requires mainly to decide the project parameters, field work including mission planning (project parameters, flight planning), image acquisition, data processing and product generation (Figure 8).

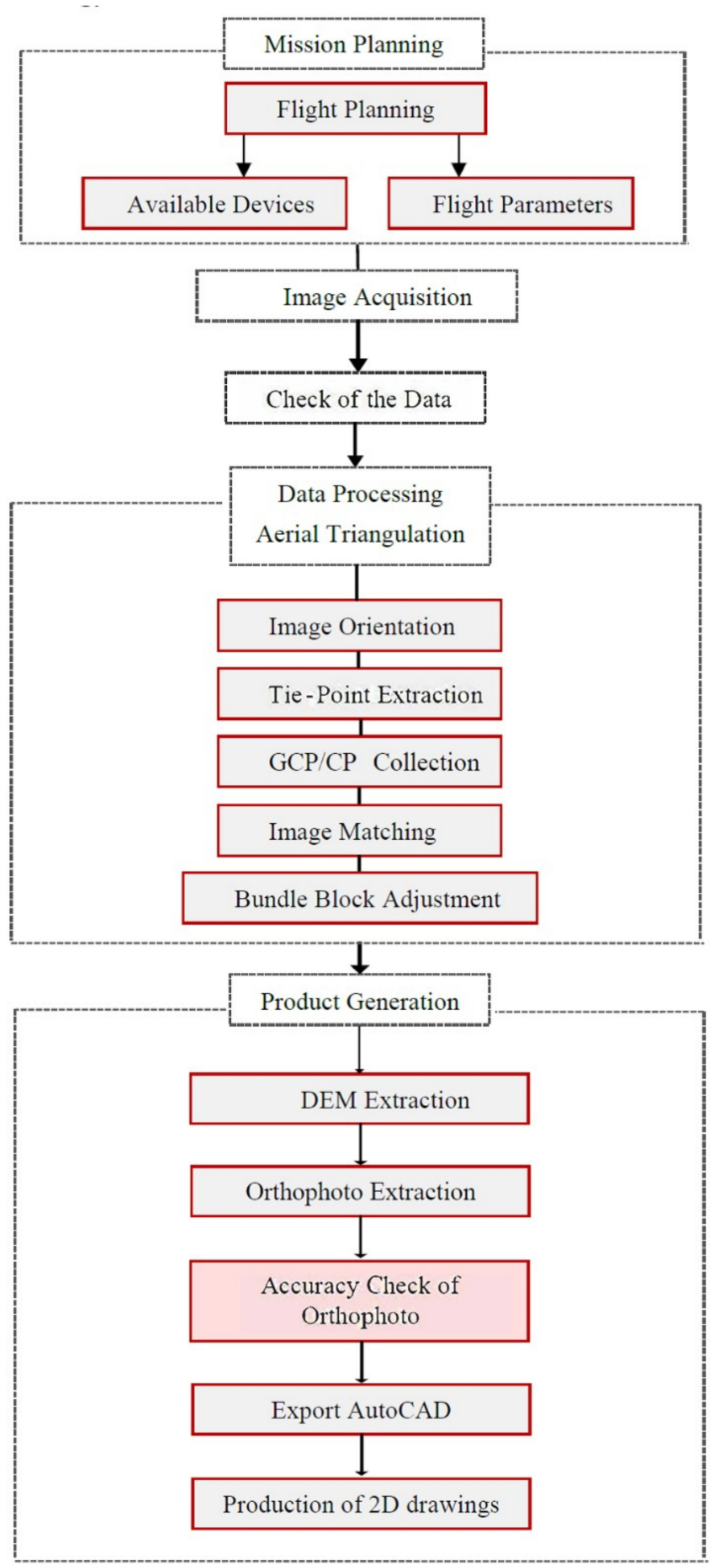

Figure 8. Flow chart of research methodology (derived from Nex and Remondino, 2014; Ref. [41]). 
Project parameters include all parameters such as flight parameters, camera calibration and ground control point (GCP) measurements, devices and digital photogrammetry parameters. Nex and Remondino (2014) prepared a general workflow and data acquisition and processing pipeline including all related parameters. After preparing all these parameters, image acquisition and then image triangulation follow the pipeline with additional parameters such as camera calibration and GCP. At the end of image triangulation, it is possible to get digital terrain models (DTMs) or digital surface models (DSMs) and digital elevation model (DEM). These outputs can be used for orthoimage generation or for different 3D modeling purposes [41].

\subsubsection{Mission Planning}

Flight mission is generally planned with related software, the required ground sample distance (GSD) (footprint) and parameters of the digital camera. Parameters such as image scale and flight heights are dependent on aim of the flight. Missions for detailed 3D model generation require high overlaps and low-altitude flights to achieve small GSDs; however, for emergency surveying or management purpose, flights require covering large areas in a few minutes, relatively at lower resolution [41]. In this project, ground control station software was used for flight planning and ground sample distance was $4.15 \mathrm{~cm}$ from $159 \mathrm{~m}$ height. The aim of this project was to see the ability of UAVs for archaeological projects, especially for 2D drawing and in desired scale which was 1:200 and 1:500. In order to cover the large area, a more durable and fixed-wing UAV was chosen.

Depending on the mission, UAV system type and environmental conditions, the flight can be done manually, with assistance or autonomously. We used autonomous option for this flight. Regarding the quality of the data, low-cost systems can be sufficient for little extensions while more expensive devices with long endurance are required for larger areas.

Appropriate aircraft image coverage is generally designed to provide about $60 \%$ forward overlap. This allows stereoscopic viewing of two overlapping images. Lateral overlap between $20 \%$ and $40 \%$ is required for complete area coverage. The usual overlap value cannot be directly used on the UAV system. In order to cover as much as possible of the area with the minimum number of images taken by the UAV system, it is necessary to investigate appropriate overlap values [42]. In this project, sidelap was $60 \%$ and overlap was $80 \%$ depending on the flight direction and archaeological area size (Table 1).

Table 1. Project parameters.

\begin{tabular}{cc}
\hline & Project Parameters \\
\hline Flight Height & $159 \mathrm{~m}$ \\
Ground resolution & $3.77 \mathrm{~cm} / \mathrm{px}$ \\
Coverage area & $1.22 \mathrm{~km}^{2}$ \\
Sidelap & $60 \%$ \\
Overlap & $80 \%$ \\
Number of strips & 3 \\
Number of images & 903 \\
Number of GCPs & 14 \\
Aligned cameras & 859 \\
Coordinate system & TUREF $/ \mathrm{TM} 33[\mathrm{EPSG}: 5255]$ \\
Dense point cloud points & $247,211,018$ \\
Tie points & 68,572 \\
Projections & 611,032 \\
Reprojection error & $0.772 \mathrm{px}$ \\
RMS reprojection error & $0.324 \mathrm{px}$ \\
Faces & $49,413,897$ \\
Vertices & $24,715,739$ \\
DEM resolution & $7.55 \mathrm{~cm} / \mathrm{px}$ \\
Orthomosaic size & $26,390 \times 35,636$ \\
\hline
\end{tabular}




\subsubsection{Image Acquisition}

For image acquisition, in order to get aerial data, SmartPlanes Freya fixed-wing UAV was used with a $1.2 \mathrm{~m}$ span, covered EPP wing and molded polycarbonate fuselage (Figure 9). It is $1.1-1.5 \mathrm{~kg}$. Its maximum flight time is between $50 \mathrm{~min}$. and $1 \mathrm{~h} 40 \mathrm{~min}$. It has different flight modes such as auto, assisted and manual and wind rating $13 \mathrm{~m} / \mathrm{s}$ with payload capacity between 200 and 600 gr. For image acquisition, Ricoh GR 16.1 MP resolution compact camera with $18.3 \mathrm{~mm}$ focal length was used. Image resolution was $4928 \times 3264$ and pixel size $4.78 \times 4.78 \mu \mathrm{m}$.
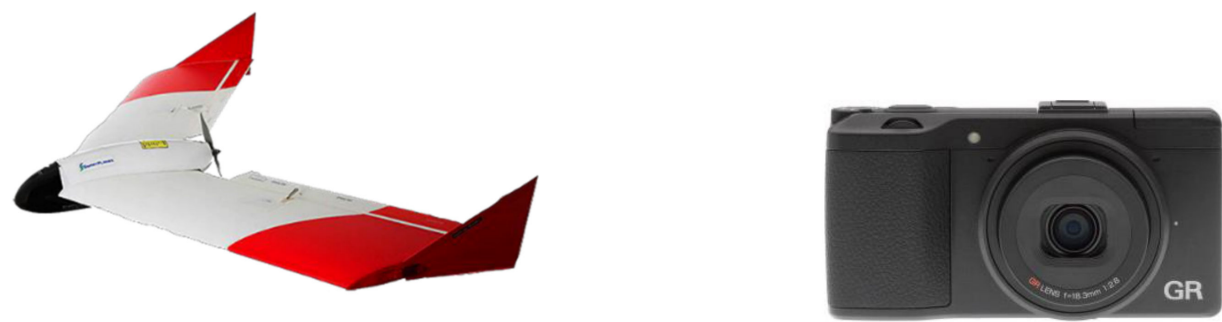

Figure 9. SmartPlanes Freya UAV (http://smartplanes.se/, accessed on 20 February 2018) (left); Ricoh GR camera (right).

Flight with UAVs can normally be done in manual, assisted (semi-autonomous) or autonomous mode. Like the other parameters, this mode varies according to the goal of the flight, platform type and environmental conditions. GNSS/INS navigation devices lead to use of autonomous flight (take-off landing and navigation) and image acquisition. Image network quality is mainly based on the flight mode. Autonomous mode of flight and image acquisition provides much more regular overlap and the geometry of the acquisition. In this case study, images were acquired with autonomous flight mode in order to get more regular overlap and the geometry of block.

GCPs have a significant role in getting better photogrammetric results. Studies show that the more GCPs there are, the more accurate photogrammetric results. In the field, a total of 14 GCPs were measured with real-time kinematic global positioning method (RTK-GPS). The flight was carried out in autonomus mode with a trained pilot. Since it was asked that archaeological area was surveyed with surroundings, the flight height was calculated according to the area size. The flight height was $159 \mathrm{~m}$. The flight trajectory and the image acquisition points were calculated depending on the scale, camera parameters, flight height, dimension of the area and the overlap. For the flight trajectory, ground control station software was used. At the end of field work, 903 images were taken in mainly 30 strips during 2 flights. During the first flight, 435 photos were taken, while during the second flight, 468 photos were taken. Image acquisition overlap was $80 \%$ and side lap was $60 \%$.

Because of the area size, shape and topographical features of the area, only 14 GCPs could be applied. The archaeological area is at risk, and thus to enter the area requires special permission. GCPs were applied according to the topographical features of the area. Since RMSE values for location and altitude were substandard according to both national and international standards, no CPs was needed.

\subsubsection{Data Processing (Aerial Triangulation)}

Image orientation and camera calibration are two principal prerequisites for any metric image reconstruction. Camera calibration relates to the problem of pixel locations in the image sequence to points in the scene. The position of the camera and camera constant must be determined to relate image plane coordinates to absolute coordinates. In addition, the location of principal point, the aspect ratio and lens distortions must be defined to relate pixel coordinates to positions in the image [43]. Photogrammetric cameras (metric) are used where it is needed to get high-accuracy measurements, such as in topographical 
applications and architectural photogrammetry. Meanwhile, digital cameras are used when lower accuracy measurements are enough. In this project, for image acquisition, Ricoh GR 16.1 MP resolution compact camera with $18.3 \mathrm{~mm}$ focal length was used, and the calibration parameters are shown in Table 2.

Table 2. Richor GR $18.3 \mathrm{~mm}$ camera calibration parameters.

\begin{tabular}{cccc}
\hline \multicolumn{4}{c}{ Richor GR 18.3 mm } \\
Camera Calibration Parameters \\
\hline Resolution & $4928 \times 3264$ & $\mathrm{~F}$ & 3872.84 \\
Type & Frame & $\mathrm{B} 1$ & 0.441328 \\
Cx & -6.25894 & $\mathrm{~B} 2$ & 2.37701 \\
Cy & 11.7735 & $\mathrm{P} 1$ & -0.000308219 \\
K1 & -0.0723221 & $\mathrm{P} 2$ & $2.6913 \times 10^{-5}$ \\
K2 & 0.091206 & $\mathrm{P} 3$ & 0 \\
K3 & -0.0196215 & $\mathrm{P} 4$ & 0 \\
K4 & 0 & & \\
\hline
\end{tabular}

In this study, for aerial image processing, PhotoScan 1.1.5 was used. Image alignment was carried out with 859 cameras (Figures 10-13) and 14 GCPs (Figure 14). The coordinate system of the project was selected TUREF/TM 33 (EPSG:5255). The images were aligned with 68,572 tie points and 14 GCPs (Table 2).

After dense point cloud model, mesh model was processed, and at the end, 49,813,987 faces and 24,715,739 vertices mesh was acquired (Figures 7 and 8).

$1.22 \mathrm{~km}^{2}$ area was covered with $3.77 \mathrm{~cm} / \mathrm{px}$ ground resolution and with $0.772 \mathrm{px}$ reprojection error with Richor GR camera. Because of the nice weather and high stability of UAV, camera locations were quite stable on archaeological area. There was just some deformation of camera locations on the north-west part of the area for a couple of centers.

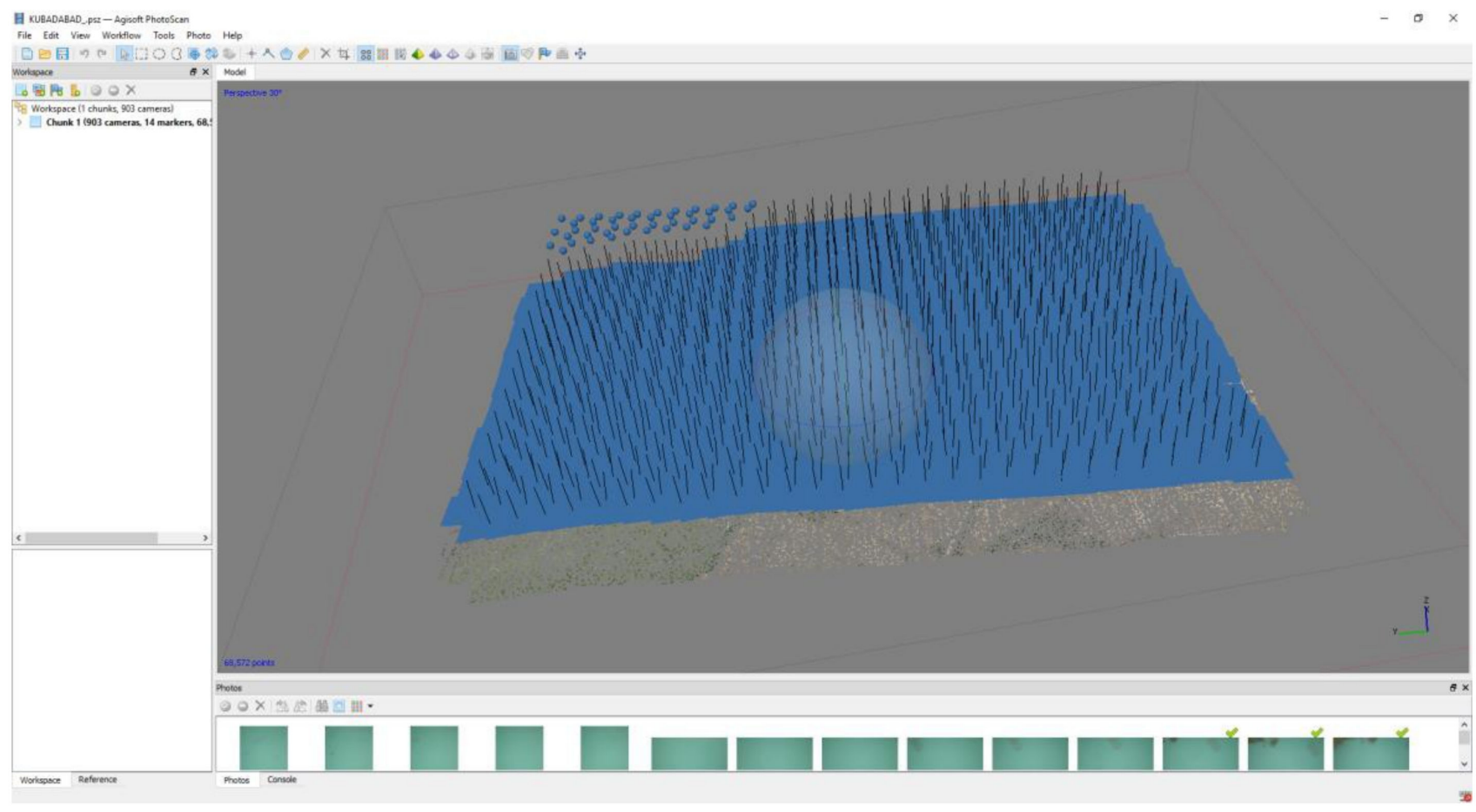

Figure 10. Camera positions in software. 


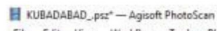

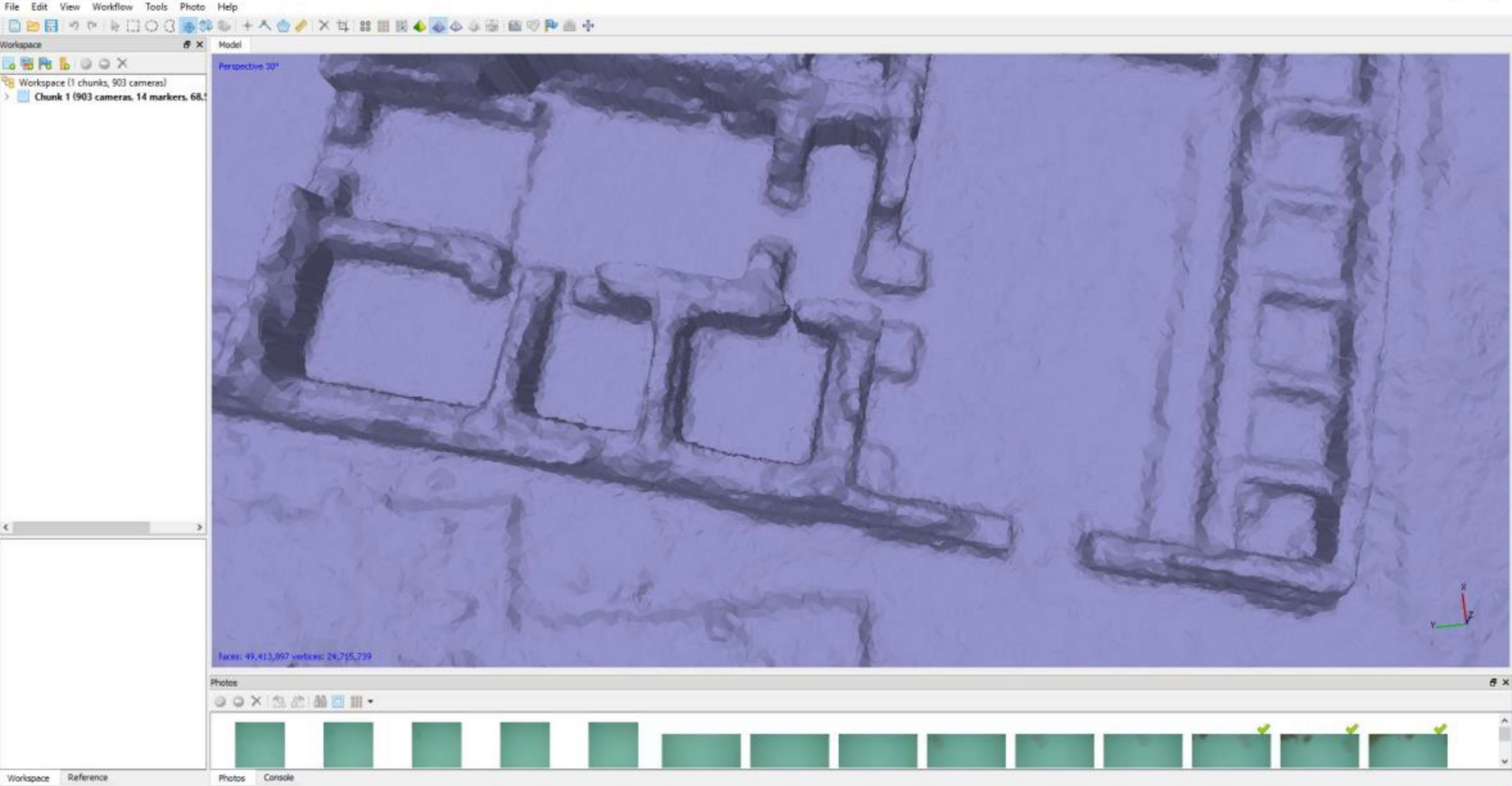

* $0 \mathbb{Q}$ e

Figure 11. Detail of Grand Palace in dense point cloud model.

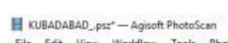

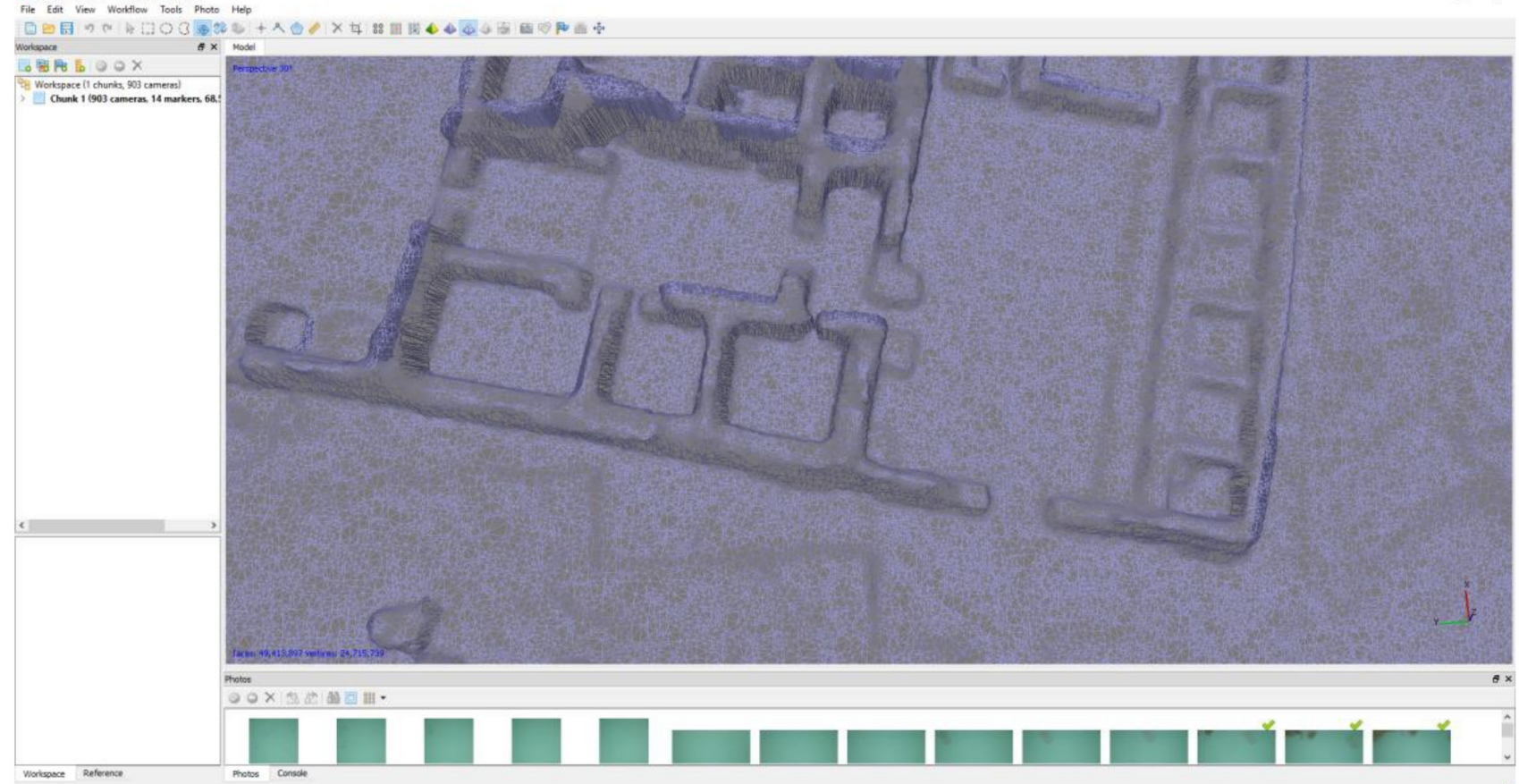

Figure 12. Detail of Grand Palace in frame model. 


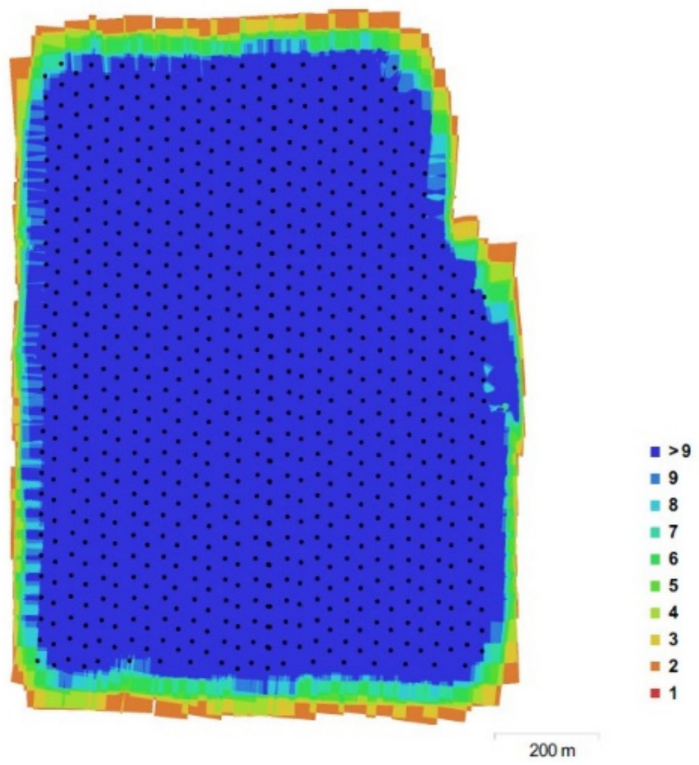

Figure 13. Camera positions.

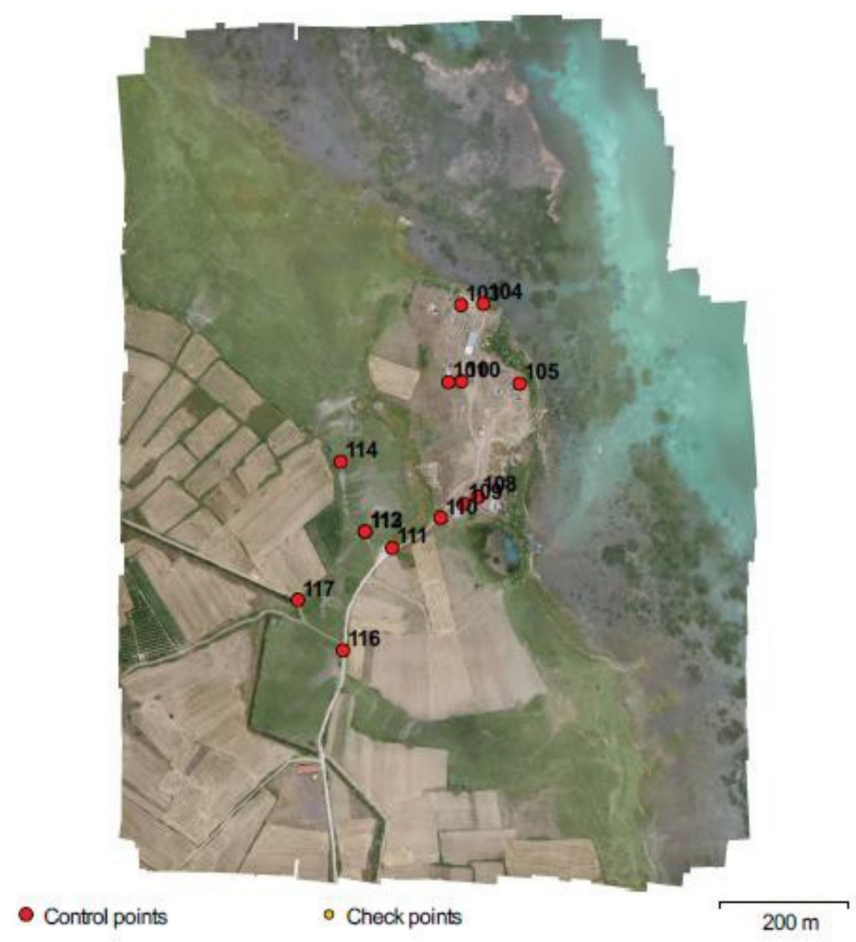

Figure 14. Ground control points.

14 GCPs' RMSE values were $4.06257 \mathrm{~cm}$ in $X, 3.32436 \mathrm{~cm}$ in $Y, 3.28841 \mathrm{~cm}$ in $Z$ and in total $6.19432 \mathrm{~cm}$ and $0.324 \mathrm{px}$ (Tables 3 and 4 ).

Table 3. GCP's RMSE values in total.

\begin{tabular}{ccccccc}
\hline Count & $\begin{array}{c}\text { X Error } \\
(\mathbf{c m})\end{array}$ & $\begin{array}{c}\text { Y Error } \\
(\mathbf{c m})\end{array}$ & $\begin{array}{c}\text { Z Error } \\
(\mathbf{c m})\end{array}$ & $\begin{array}{c}\text { XY Error } \\
(\mathbf{c m})\end{array}$ & Total $(\mathbf{c m})$ & $\begin{array}{c}\text { Image } \\
(\text { pix })\end{array}$ \\
\hline 14 & 4.06257 & 3.32436 & 3.28841 & 5.24937 & 6.19432 & 0.324 \\
\hline
\end{tabular}


Table 4. GCP's RMSE values.

\begin{tabular}{cccccc}
\hline Label & X Error $(\mathbf{c m})$ & Y Error $(\mathbf{c m})$ & Z Error $(\mathbf{c m})$ & Total $(\mathbf{c m})$ & Image $($ pix) \\
\hline 100 & 6.11981 & 5.95244 & -1.88219 & 8.74221 & $0.269(23)$ \\
101 & 4.45511 & -2.77318 & 3.11042 & 6.10027 & $0.310(24)$ \\
103 & -4.27609 & -1.04231 & -2.03174 & 4.84761 & $0.266(18)$ \\
104 & -3.38464 & -1.1302 & 1.253 & 3.78194 & $0.183(21)$ \\
105 & 3.75177 & -5.17337 & -0.0764271 & 6.39103 & $0.121(22)$ \\
108 & -0.994673 & 2.90823 & 6.45443 & 7.1489 & $0.346(25)$ \\
109 & -8.0377 & 3.28298 & -6.07461 & 10.5964 & $0.556(24)$ \\
110 & 2.599 & -2.00871 & -1.591775 & 3.65012 & $0.255(27)$ \\
111 & 2.75833 & 1.93097 & 2.94591 & 4.47386 & $0.183(16)$ \\
112 & -3.95106 & 2.24095 & -5.24227 & 6.93643 & $0.567(14)$ \\
113 & 2.49822 & -1.3361 & 2.72138 & 3.92839 & $0.495(15)$ \\
114 & -1.66697 & 4.1478 & -1.49671 & 4.71415 & $0.051(4)$ \\
116 & -3.39311 & -0.623031 & -1.28622 & 3.68181 & $0.177(17)$ \\
117 & 3.72089 & -5.57416 & 1.97885 & 6.988 & $0.118(16)$ \\
Total & $\mathbf{4 . 0 6 2 5 7}$ & $\mathbf{3 . 3 2 4 3 6}$ & $\mathbf{3 . 2 8 8 4 1}$ & $\mathbf{6 . 1 9 4 3 2}$ & $\mathbf{0 . 3 2 4}$ \\
\hline
\end{tabular}

The final orthophoto size was 26,390 × 35,636 and 1.72 GB file size (Figures 15 and 16). In this study, an aircraft model UAV was used in order to get large-scale mapping and 2D drawings of archaeological area. For this project, the data were quite dense, and it was difficult to manage the data. For this kind of big area, hardware should be powerful enough. Since the management of the data was difficult, data processing took time, and even taking the screenshots from the computer took time and caused crash in the computer.

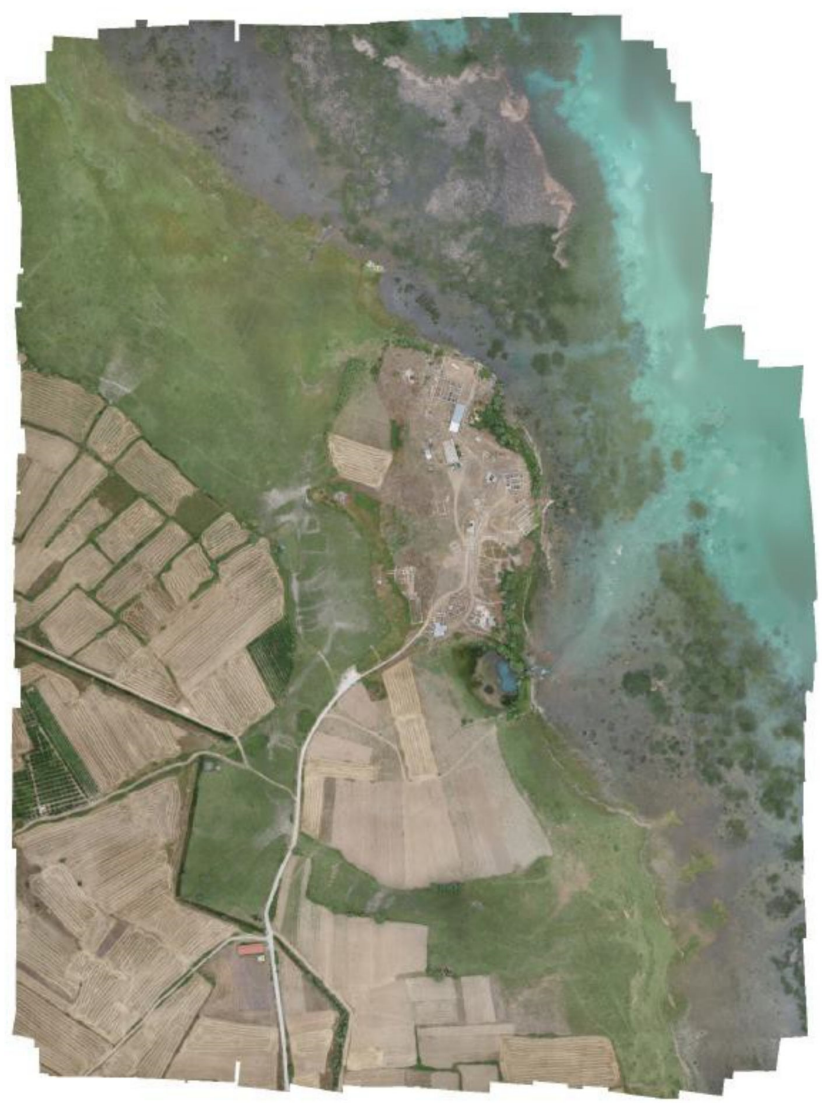

Figure 15. Orthophoto of the archaeological area. 


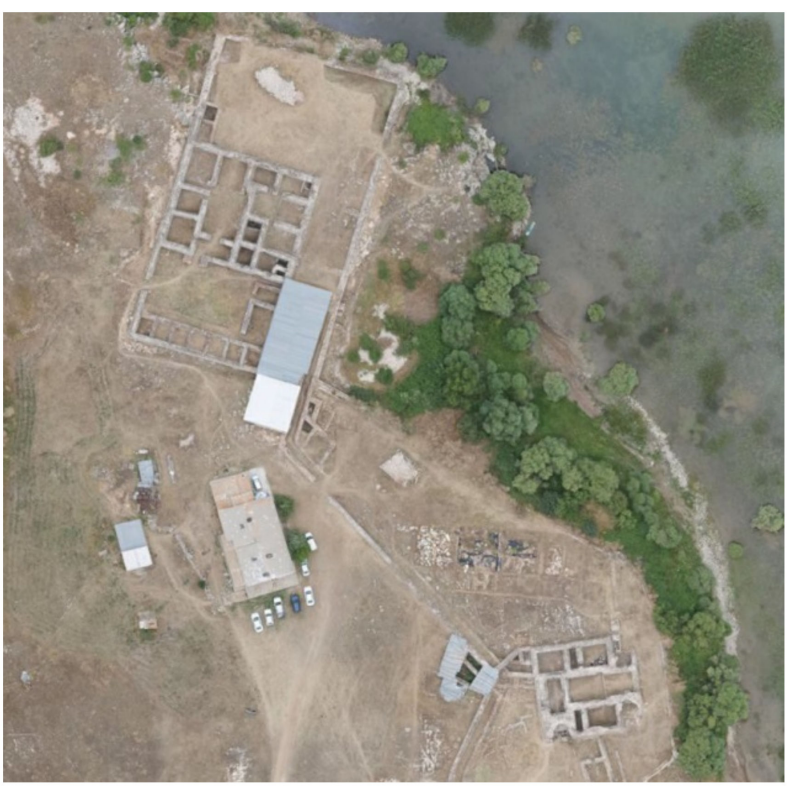

Figure 16. Detail of the Grand Palace and the Small Palace in Orthophoto.

With a typical photogrammetric pipeline, 3D results such as DSM (digital surface model) or DTM (digital terrain model), contour lines, textured 3D models, vector data, etc., can be produced in a reasonable automated way. Digital elevation model (DEM), one of the products of UAV photogrammetry, can be defined as a digital model or 3D representation of a terrain surface created from elevation data. A DEM can be a raster file consisting of each record with 3D element usually associated with geographic coordinates. Digital terrain model (DTM) is a DEM shape of the ground, while digital surface model (DSM) is a DEM of the shape of the surface (including vegetation, infra-structures, etc.). In photogrammetry, DEMs are a by-product resulting from the interpolation of extremely dense 3D point clouds extracted from imagery. The quality of a DEM depends on horizontal and vertical accuracy. In order to check DEM accuracy, RMSE and standard deviation (SV) calculations can be used [44]. In this project, DEM was in $7.55 \mathrm{~cm} / \mathrm{px}$ resolution and 176 points $/ \mathrm{m}^{2}$ (Figure 17 ).

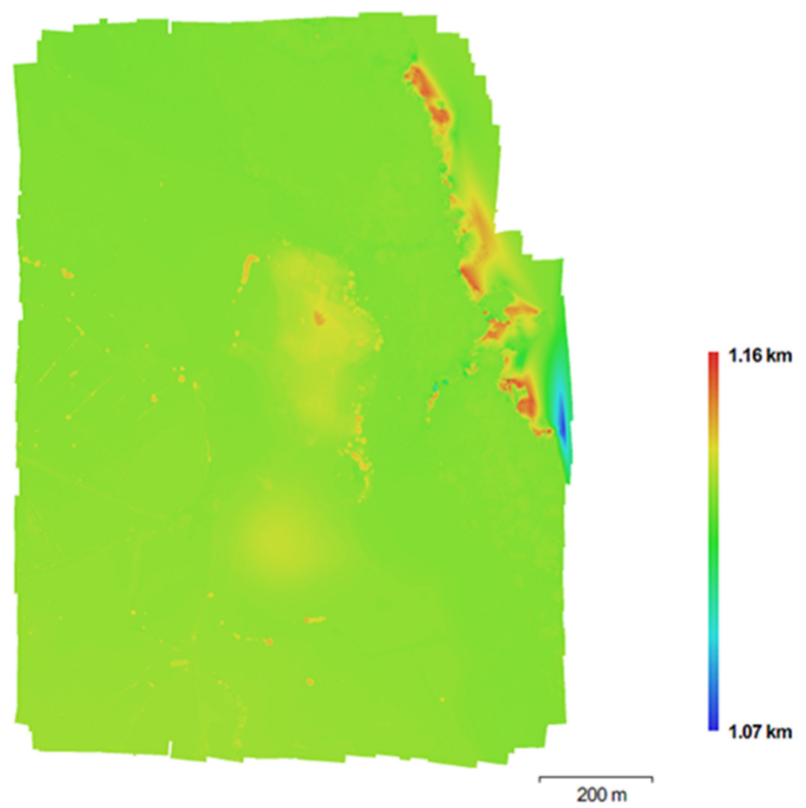

Figure 17. Reconstructed DEM is in $7.55 \mathrm{~cm} / \mathrm{px}$ resolution and 176 points $/ \mathrm{m}^{2}$. 
The resolution of the final orthophoto is high, and even single structures such as stones can be seen in orthophoto and 3D model. The main difficulties were in vertical walls; however, since their height was not much from the ground, it was possible to draw in AutoCAD for 2D purpose (Figure 18). For these kinds of parts, it would be another way to make laser scanning and to combine both TLS and aerial data sets. For future work, it is aimed to combine both data and to prepare a reconstructed model of the area. According to the experience, UAV data can be used for large-scale mapping (more than 1:500) and 2D drawing.

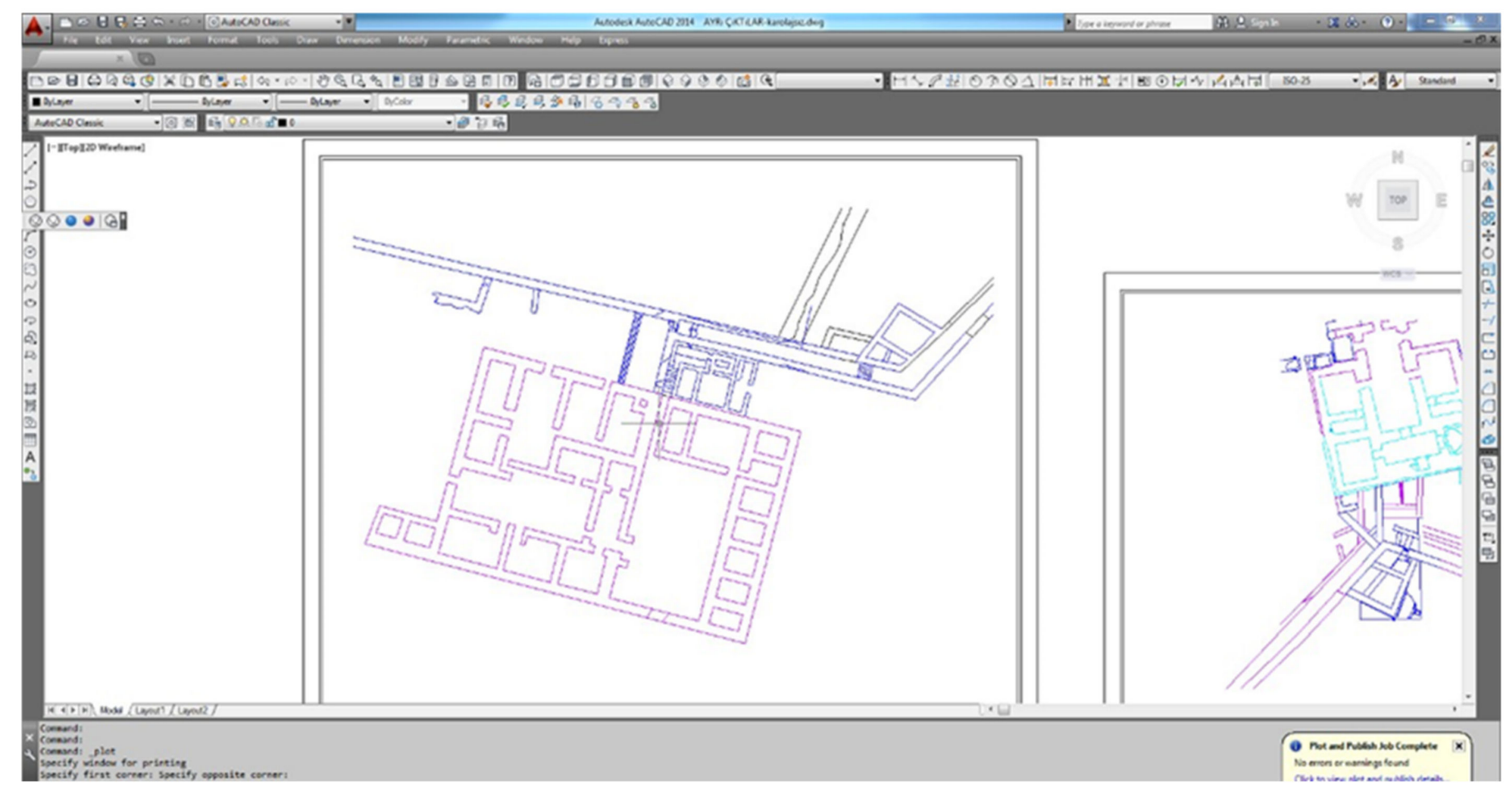

Figure 18. 2D drawing in AutoCAD.

\section{Results}

\subsection{Specific Requirements}

To check the data accuracy, the ASPRS (American Society for Photogrammetry and Remote Sensing) published draft report in 2014 was taken as a reference. The ASPRS is a scientific association founded in 1934, and their mission is to advance knowledge and improve understanding of mapping sciences to promote responsible applications of photogrammetry, remote sensing, geographic information systems (GISs) and supporting technologies (www.asprs.org). They published ASPRS Accuracy Standards for Digital Geospatial Data on 21 March 2014 with the objective to replace the existing ASPRS Accuracy Standards for Large-Scale Maps (1990) and the ASPRS Guidelines Vertical Accuracy Reporting for Lidar Data (2004) to better address current technologies.

The standard defines specific accuracy classes and associated RMSE thresholds for digital orthoimagery, digital planimetric data and digital elevation data (Table 3). Accuracy classes have been revised and upgraded from the 1990 standard to address the higher accuracies achievable with newer technologies. The standard also includes additional accuracy measures, such as ortho seamlines, aerial triangulation accuracy, horizontal accuracy of elevation data and the required number and spatial distribution of check points. The standard is intended to be technology-independent and the base standard upon which future work can build.

When required, horizontal accuracy can be tested by comparing the planimetric coordinates of well-defined points in the data set with coordinates of the same points from an independent source of higher accuracy. Vertical accuracy can be tested by comparing 
the elevations in the data set with elevations of the same points as determined from an independent source of higher accuracy.

When errors are normally distributed, accuracy can be performed with RMSE values, standard deviations, mean errors, maximum and minimum errors and unitless skew kurtosis values. When errors are not normally distributed, alternative methods can be used. If the number of test points (check points) is sufficient, testing and reporting can be performed using 95th percentile errors.

Using metric units, the ASPRS recommends 100 static vertical check points for the first 2500 square kilometer area within the project. This provides a statistically defensible number of samples on which to base a valid vertical accuracy assessment. For horizontal testing of areas $>2500 \mathrm{~km}^{2}$, clients should determine the number of additional horizontal check points, if any, based on criteria such as resolution of imagery and extent of urbanization.

For vertical testing of areas $>2500 \mathrm{~km}^{2}$, add five additional vertical check points for each additional $500 \mathrm{~km}^{2}$ area. Each additional set of five vertical check points for $500 \mathrm{~km}^{2}$ would include three check points for NVA (non-vegetated vertical accuracy) and two for VVA (vegetated vertical accuracy) (Table 5) [35]. The recommended number and distribution of NVA and VVA check points may vary depending on the importance of different land-cover categories and client requirements.

Table 5. Recommended number of check points based on area [37].

\begin{tabular}{|c|c|c|c|c|}
\hline \multirow{2}{*}{$\begin{array}{l}\text { Project Area (Square } \\
\text { Kilometers) }\end{array}$} & $\begin{array}{c}\text { Horizontal Accuracy } \\
\text { Testing of } \\
\text { Orthoimagery and }\end{array}$ & \multicolumn{3}{|c|}{ Vertical and Horizontal Accuracy Testing of Elevation Data Sets } \\
\hline & $\begin{array}{l}\text { Total Number of Static } \\
\text { 2D/3D Check Points } \\
\text { (Clearly Defined } \\
\text { Points) }\end{array}$ & $\begin{array}{l}\text { Number of Static 3D } \\
\text { Check Points in NVA }\end{array}$ & $\begin{array}{l}\text { Number of Static 3D } \\
\text { Check Points in VVA }\end{array}$ & $\begin{array}{c}\text { Total Number of } \\
\text { Static 3D Check } \\
\text { Points }\end{array}$ \\
\hline$\leq 500$ & 20 & 20 & 5 & 25 \\
\hline $501-750$ & 25 & 20 & 10 & 30 \\
\hline $751-1000$ & 30 & 25 & 15 & 40 \\
\hline $1001-1250$ & 35 & 30 & 20 & 50 \\
\hline $1251-1500$ & 40 & 35 & 25 & 60 \\
\hline $1501-1750$ & 45 & 40 & 30 & 70 \\
\hline $1751-2000$ & 50 & 45 & 35 & 80 \\
\hline $2001-2250$ & 55 & 50 & 40 & 90 \\
\hline $2251-2500$ & 60 & 55 & 45 & 100 \\
\hline
\end{tabular}

In the Kubad Abad project, the project area was $1.22 \mathrm{~km}^{2}$, a total of 14 GCPs were used, and the area was vegetated.

\subsection{Horizontal and Vertical Accuracy Assessment}

\subsubsection{Horizontal Accuracy Assessment}

Horizontal accuracy is the horizontal component of the positional accuracy of a data set with respect to a horizontal datum, defined at the $95 \%$ confidence level. Horizontal accuracy is to be assessed using root mean square error (RMSE) statistics, while vertical accuracy is to be assessed using RMSE statistics in non-vegetated terrain and 95th percentile statistics in vegetated terrain (Table 6).

Horizontal accuracy,

$$
\operatorname{RMSEx}=\operatorname{sqrt}\left[\left(\mathrm{x}_{\text {data, } \mathrm{i}}-\mathrm{x}_{\text {check, }}\right)^{2} / \mathrm{n}\right]
$$




$$
\text { RMSEy }=\operatorname{sqrt}\left[\left(\mathrm{y}_{\text {data, }} \mathrm{i}-\mathrm{y}_{\text {check, }}\right)^{2} / \mathrm{n}\right]
$$

RMSEx, the horizontal linear RMSE in the $X$ direction.

RMSEy, the horizontal linear RMSE in the Y direction .

$\mathrm{x}_{\mathrm{data}, \mathrm{i}}$ and $\mathrm{y}_{\mathrm{data}, \mathrm{i}}$ are the coordinates of the $i$ th check point in the data set.

$\mathrm{x}_{\text {check,i }}$ and $\mathrm{y}_{\text {check,i }}$ are the coordinates of the $i$ th check point in the independent source of higher accuracy (in the model), $n$ is the number of check points tested, and $i$ is an integer ranging from 1 to $\mathrm{n}$. In this project,

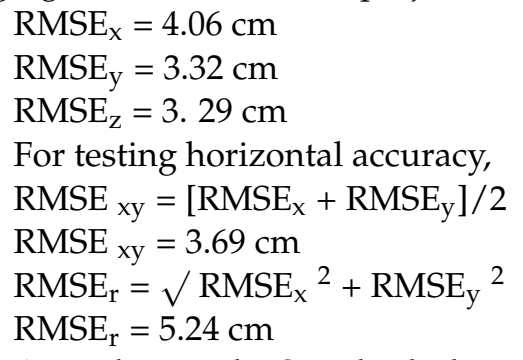

According to the Standards, horizontal accuracy at a 95\% confidence level should be $\leq 2.45 \times X$ which for this project is

Accuracy $\mathrm{r}=1.7308 \times 5.24$

Accuracy $\mathrm{r}=9.06 \mathrm{~cm}$

Table 6. Horizontal accuracy values depending on the $x$ values [37].

\begin{tabular}{ccccc}
\hline $\begin{array}{c}\text { Horizontal } \\
\text { Accuracy Class }\end{array}$ & $\begin{array}{c}\text { RMSE }_{\mathrm{x}} \text { and } \\
\mathrm{RMSE}_{\mathrm{y}}(\mathrm{cm})\end{array}$ & RMSE $_{\mathrm{r}}(\mathrm{cm})$ & $\begin{array}{c}\text { Horizontal Accuracy at 95\% } \\
\text { Confidence Level (cm) }\end{array}$ & $\begin{array}{c}\text { Orthoimagery Mosaic } \\
\text { Seamline Mismatch (cm) }\end{array}$ \\
\hline $\mathrm{X}-\mathrm{cm}$ & $\leq \mathrm{X}$ & $\leq 1.41 \times \mathrm{X}$ & $\leq 2.45 \times \mathrm{X}$ & $\leq 2 \times \mathrm{X}$ \\
\hline
\end{tabular}

According to Table 7 horizontal accuracy examples for digital orthophotos, the values of the Kubad Abad project are between the required values of ASPRS Standards with the values

RMSE $_{x y}=3.69 \mathrm{~cm}$

$\mathrm{RMSE}_{\mathrm{r}}=5.24 \mathrm{~cm}$

Accuracy $\mathrm{r}=9.06 \mathrm{~cm}$

Table 7. Horizontal accuracy/quality example standards for digital orthoimagery [37].

\begin{tabular}{cccc}
\hline $\begin{array}{c}\text { Horizontal Accuracy Class } \\
\text { RMSEx and RMSEy }(\mathbf{c m})\end{array}$ & RMSEr (cm) & $\begin{array}{c}\text { Orthoimage Mosaic Seamline } \\
\text { Maximum Mismatch } \mathbf{( c m})\end{array}$ & $\begin{array}{c}\text { Horizontal Accuracy at the } \\
\text { 95\% Confidence Level }(\mathbf{c m})\end{array}$ \\
\hline $\mathbf{0 . 6 3}$ & 0.9 & 1.3 & 1.5 \\
\hline $\mathbf{1 . 2 5}$ & 1.8 & 2.5 & 3.1 \\
\hline $\mathbf{2 . 5 0}$ & 3.5 & 5.0 & 6.1 \\
\hline $\mathbf{5 . 0 0}$ & 7.1 & 10.0 & 12.2 \\
\hline $\mathbf{7 . 5 0}$ & 10.6 & 15.0 & 18.4 \\
\hline $\mathbf{1 0 . 0 0}$ & 14.1 & 20.0 & 24.5 \\
\hline $\mathbf{1 2 . 5 0}$ & 17.7 & 25.0 & 30.6 \\
\hline $\mathbf{1 5 . 0 0}$ & 21.2 & 30.0 & 36.7 \\
\hline $\mathbf{1 7 . 5 0}$ & 24.7 & 35.0 & 42.8 \\
\hline $\mathbf{2 0 . 0 0}$ & 28.3 & 40.0 & 49.0 \\
\hline $\mathbf{2 2 . 5 0}$ & 31.8 & 45.0 & 55.1 \\
\hline $\mathbf{2 5 . 0 0}$ & 35.4 & 50.0 & 61.2 \\
\hline
\end{tabular}


Table 7. Cont.

\begin{tabular}{cccc}
\hline $\begin{array}{c}\text { Horizontal Accuracy Class } \\
\text { RMSEx and RMSEy }(\mathbf{c m})\end{array}$ & RMSEr (cm) & $\begin{array}{c}\text { Orthoimage Mosaic Seamline } \\
\text { Maximum Mismatch } \mathbf{( c m )}\end{array}$ & $\begin{array}{c}\text { Horizontal Accuracy at the } \\
\text { 95\% Confidence Level }(\mathbf{c m})\end{array}$ \\
\hline $\mathbf{2 7 . 5 0}$ & 38.9 & 55.0 & 67.3 \\
\hline $\mathbf{3 0 . 0 0}$ & 42.4 & 60.0 & 73.4 \\
\hline $\mathbf{4 5 . 0 0}$ & 63.6 & 90.0 & 110.1 \\
\hline $\mathbf{6 0 . 0 0}$ & 84.9 & 120.0 & 146.9 \\
\hline $\mathbf{7 5 . 0 0}$ & 106.1 & 150.0 & 183.6 \\
\hline $\mathbf{1 0 0 . 0 0}$ & 141.4 & 200.0 & 244.8 \\
\hline $\mathbf{1 5 0 . 0 0}$ & 212.1 & 300.0 & 367.2 \\
\hline $\mathbf{2 0 0 . 0 0}$ & 282.8 & 400.0 & 489.5 \\
\hline $\mathbf{2 5 0 . 0 0}$ & 353.6 & 500.0 & 611.9 \\
\hline $\mathbf{3 0 0 . 0 0}$ & 424.3 & 600.0 & 734.3 \\
\hline $\mathbf{5 0 0 . 0 0}$ & 707.1 & 1000.0 & 1223.9 \\
\hline $\mathbf{1 0 0 0 . 0 0}$ & 1414.2 & 2000.0 & 2447.7 \\
\hline
\end{tabular}

Ground sample distance (GSD) is the linear dimension of a sample pixel's footprint on the ground. In ASPRS Standards, GSD is assumed to be the value computed using the camera focal length and camera height above average mean terrain. In the Kubad Abad project, GSD can be calculated as

$$
\begin{gathered}
\mathrm{GSD}=(\mathrm{H} / \mathrm{f}) \mu \\
\mu=\mathrm{W} / \mathrm{Sw}=\mathrm{H} / \mathrm{Sh}
\end{gathered}
$$

where $\mathrm{H}$ is flight height $(\mathrm{m}), \mathrm{f}$ is focal length (mm), GSD is ground sample distance $(\mathrm{m}), \mu$ is pixel size $(\mu \mathrm{m}), \mathrm{W}$ is the width of CCD $(\mathrm{mm}), \mathrm{H}$ is the height of $\mathrm{CDD}(\mathrm{mm}), \mathrm{Sw}$ is the number of pixels for $\mathrm{W}$, and $\mathrm{Sh}$ is the number of pixels for $\mathrm{H}$.

In this project, $\mathrm{GSD}=4.15 \mathrm{~cm}$.

According to ASPRS Standards, depending on the horizontal accuracy values, the GSD value should be between 1.25 and $5.0 \mathrm{~cm}$ when RMSExy value is between 2.5 and $5 \mathrm{~cm}$ (Table 8). In our study, GSD value $4.15 \mathrm{~cm}$ is within this interval with $3.69 \mathrm{~cm}$ RMSE xy.

Table 8. Horizontal accuracy/quality examples for high-accuracy digital planimetric data.

\begin{tabular}{llllll}
\hline & \multicolumn{2}{c}{ ASPRS 2014 } & \multicolumn{2}{c}{ Equivalent to Map Scale in } \\
\hline $\begin{array}{l}\text { Horizontal Accuracy } \\
\text { Class RMSEx and } \\
\text { RMSEy }(\mathbf{c m})\end{array}$ & $\begin{array}{l}\text { RMSEr } \\
(\mathbf{c m})\end{array}$ & $\begin{array}{l}\text { Horizontal Accuracy at } \\
\text { the 95\% Confidence } \\
\text { Level }(\mathbf{c m})\end{array}$ & $\begin{array}{l}\text { Approximate } \\
\text { GSD of Source } \\
\text { Imagery (cm) }\end{array}$ & $\begin{array}{c}\text { ASPRS1990 } \\
\text { Class 1 }\end{array}$ & $\begin{array}{c}\text { ASPRS1990 } \\
\text { Class 2 }\end{array}$ \\
\hline $\mathbf{0 . 6 3}$ & 0.9 & 1.5 & 0.31 to 0.63 & $1: 25$ & $1: 12.5$ \\
\hline $\mathbf{1 . 2 5}$ & 1.8 & 3.1 & 0.63 to 1.25 & $1: 50$ & $1: 25$ \\
\hline $\mathbf{2 . 5}$ & 3.5 & 6.1 & 1.25 to 2.5 & $1: 100$ & $1: 50$ \\
\hline $\mathbf{5 . 0}$ & 7.1 & 12.2 & 2.5 to 5.0 & $1: 200$ & $1: 100$ \\
\hline $\mathbf{7 . 5}$ & 10.6 & 18.4 & 3.8 to 7.5 & $1: 300$ & $1: 150$ \\
\hline $\mathbf{1 0 . 0}$ & 14.1 & 24.5 & 5.0 to 10.0 & $1: 400$ & $1: 200$ \\
\hline $\mathbf{1 2 . 5}$ & 17.7 & 30.6 & 6.3 to 12.5 & $1: 500$ & $1: 250$ \\
\hline $\mathbf{1 5 . 0}$ & 21.2 & 36.7 & 7.5 to 15.0 & $1: 600$ & $1: 300$ \\
\hline
\end{tabular}


Table 8. Cont.

\begin{tabular}{llllll}
\hline & \multicolumn{2}{c}{ ASPRS 2014 } & \multicolumn{2}{c}{ Equivalent to Map Scale in } \\
\hline $\begin{array}{l}\text { Horizontal Accuracy } \\
\begin{array}{l}\text { Class RMSEx and } \\
\text { RMSEy (cm) }\end{array}\end{array}$ & $\begin{array}{l}\text { RMSEr } \\
(\mathbf{c m})\end{array}$ & $\begin{array}{l}\text { Horizontal Accuracy at } \\
\text { the 95\% Confidence } \\
\text { Level }(\mathbf{c m})\end{array}$ & $\begin{array}{l}\text { Approximate } \\
\text { GSD of Source } \\
\text { Imagery (cm) }\end{array}$ & $\begin{array}{c}\text { ASPRS1990 } \\
\text { Class 1 }\end{array}$ & $\begin{array}{c}\text { ASPRS1990 } \\
\text { Class 2 }\end{array}$ \\
\hline $\mathbf{1 7 . 5}$ & 24.7 & 42.8 & 8.8 to 17.5 & $1: 700$ & $1: 350$ \\
\hline $\mathbf{2 0 . 0}$ & 28.3 & 49.0 & 10.0 to 20.0 & $1: 800$ & $1: 400$ \\
\hline $\mathbf{2 2 . 5}$ & 31.8 & 55.1 & 11.3 to 22.5 & $1: 900$ & $1: 450$ \\
\hline $\mathbf{2 5 . 0}$ & 35.4 & 61.2 & 12.5 to 25.0 & $1: 1000$ & $1: 500$ \\
\hline $\mathbf{2 7 . 5}$ & 38.9 & 67.3 & 13.8 to 27.5 & $1: 1100$ & $1: 550$ \\
\hline $\mathbf{3 0 . 0}$ & 42.4 & 73.4 & 15.0 to 30.0 & $1: 1200$ & $1: 600$ \\
\hline
\end{tabular}

\subsubsection{Vertical Accuracy Assessment}

Vertical accuracy is the measure of positional accuracy of a data set with respect to a specified vertical datum. According to ASPRS accuracy standards (Table 9), elevation data have mainly ten accuracy levels relevant to technologies such as mobile mapping systems, unmanned aerial systems, airborne or satellite imagery, Lidar or IFSAR (interferometric synthetic aperture radar).

$$
\operatorname{RMSE} \mathrm{z}=\operatorname{sqrt}\left[\left(\mathrm{z}_{\text {data, }, \mathrm{i}}-\mathrm{z}_{\text {check,i }}\right) 2 / \mathrm{n}\right]
$$

where

$\mathrm{z}_{\mathrm{data}, \mathrm{i}}$ is the vertical coordinate of the ith check point in the data set.

$z_{c h e c k, i}$ is the vertical coordinate of the ith check point in the independent source of higher accuracy.

$\mathrm{n}=$ the number of points being checked.

$i$ is an integer from 1 to $n$.

It is assumed that systematic errors were eliminated as best as possible. If the vertical error is normally distributed, the factor 1.9600 is applied to compute linear error at the $95 \%$ confidence level (Greenwalt and Schultz, 1968). Therefore, vertical accuracy, Accuracy z, reported according to the NSSDA, should be computed by the following formula:

Accuracy $\mathrm{z}=1.96 \mathrm{X}$ RMSEz.

Table 9. Accuracy standards for digital elevation data.

\begin{tabular}{|c|c|c|c|c|c|c|}
\hline \multirow[b]{2}{*}{$\begin{array}{c}\text { Vertical } \\
\text { Accuracy Class }\end{array}$} & \multicolumn{3}{|c|}{ Absolute Accuracy } & \multicolumn{3}{|c|}{ Relative Accuracy (Where Applicable) } \\
\hline & $\begin{array}{l}\text { RMSEz } \\
\text { Non- } \\
\text { Vegetated } \\
\text { (cm) }\end{array}$ & $\begin{array}{l}\text { NVA at } 95 \% \\
\text { Confidence } \\
\text { Level } \\
\text { (cm) }\end{array}$ & $\begin{array}{l}\text { VVA at } \\
\text { 95th } \\
\text { Percentile } \\
\text { (cm) }\end{array}$ & $\begin{array}{l}\text { Within-Swath } \\
\text { Hard Surface } \\
\text { Repeatability } \\
\text { (Max Diff) } \\
\text { (cm) }\end{array}$ & $\begin{array}{c}\text { Swath-to-Swath } \\
\text { Non-Vegetated } \\
\text { Terrain (RMSDz) } \\
\text { (cm) }\end{array}$ & $\begin{array}{c}\text { Swath-to- } \\
\text { Swath } \\
\text { Non-Vegetated } \\
\text { Terrain (Max } \\
\text { Diff) (cm) }\end{array}$ \\
\hline $\mathrm{X}-\mathrm{cm}$ & $\leq \mathrm{X}$ & $\leq 1.96 \times X$ & $\leq 3.00 \times X$ & $\leq 0.60 \times X$ & $\leq 0.80 \times X$ & $\leq 1.60 \times X$ \\
\hline
\end{tabular}

Absolute accuracy is a measure that accounts for all systematic and random errors in a data set (Table 10).

In the Kubad Abad porject, $R M S E_{z}=3.29 \mathrm{~cm}$

Accuracy $_{z}=1.96 \times 3.29=6.49 \mathrm{~cm}$ (NVA at $95 \%$ confidence level $)$

$3 \mathrm{X} 3.29=9.87 \mathrm{~cm}$ (VVA at 95th percentile) 
Table 10. Vertical accuracy/quality examples for digital elevation data.

\begin{tabular}{|c|c|c|c|c|c|c|}
\hline \multirow[b]{2}{*}{$\begin{array}{c}\text { Vertical } \\
\text { Accuracy Class }\end{array}$} & \multicolumn{3}{|c|}{ Absolute Accuracy } & \multicolumn{3}{|c|}{ Relative Accuracy (Where Applicable) } \\
\hline & $\begin{array}{l}\text { RMSEz } \\
\text { Non- } \\
\text { Vegetated } \\
\text { (cm) }\end{array}$ & $\begin{array}{l}\text { NVA at } 95 \% \\
\text { Confidence } \\
\text { Level } \\
\text { (cm) }\end{array}$ & $\begin{array}{l}\text { VVA at } \\
\text { 95th } \\
\text { Percentile } \\
\text { (cm) }\end{array}$ & $\begin{array}{l}\text { Within-Swath } \\
\text { Hard Surface } \\
\text { Repeatability } \\
\text { (Max Diff) } \\
\text { (cm) }\end{array}$ & $\begin{array}{l}\text { Swath-to-Swath } \\
\text { Non-Veg Terrain } \\
\text { (RMSDz) } \\
\text { (cm) }\end{array}$ & $\begin{array}{c}\text { Swath-to-Swath } \\
\text { Non-Veg Terrain } \\
\text { (Max Diff) (cm) }\end{array}$ \\
\hline $1 \mathrm{~m}$ & 1.0 & 2.0 & 3 & 0.6 & 0.8 & 1.6 \\
\hline $2.5-\mathrm{cm}$ & 2.5 & 4.9 & 7.5 & 1.5 & 2 & 4 \\
\hline $5-\mathrm{cm}$ & 5.0 & 9.8 & 15 & 3 & 4 & 8 \\
\hline $10-\mathrm{cm}$ & 10.0 & 19.6 & 30 & 6 & 8 & 16 \\
\hline $15-\mathrm{cm}$ & 15.0 & 29.4 & 45 & 9 & 12 & 24 \\
\hline $20-\mathrm{cm}$ & 20.0 & 39.2 & 60 & 12 & 16 & 32 \\
\hline $33.3-\mathrm{cm}$ & 33.3 & 65.3 & 100 & 20 & 26.7 & 53.3 \\
\hline $66.7-\mathrm{cm}$ & 66.7 & 130.7 & 200 & 40 & 53.3 & 106.7 \\
\hline $100-\mathrm{cm}$ & 100.0 & 196.0 & 300 & 60 & 80 & 160 \\
\hline $333.3-\mathrm{cm}$ & 333.3. & 653.3 & 1000 & 200 & 266.7 & 533.3 \\
\hline
\end{tabular}

According to ASPRS Standards, horizontal and vertical accuracy should be reported as in the following.

This data set was tested to meet ASPRS Positional Accuracy Standards for Digital Geospatial Data (2014) for a $5(\mathrm{~cm}) \mathrm{RMSE}_{\mathrm{x}} / \mathrm{RMSE}_{\mathrm{y}}$ horizontal accuracy class. Actual positional accuracy was found to be $\mathrm{RMSE}_{\mathrm{x}}=4.06 \mathrm{~cm}$ and $\mathrm{RMSE}_{\mathrm{y}}=3.32 \mathrm{~cm}$ which equates to $\pm 9.04 \mathrm{~cm}$ at a $95 \%$ confidence level.

This data set was tested to meet ASPRS Positional Accuracy Standards for Digital Geospatial Data (2014) for a $5(\mathrm{~cm}) R M S E_{z}$ vertical accuracy class. Actual NVA accuracy was found to be $R M S E_{z}=3.29 \mathrm{~cm}$, equating to $\pm 6.49 \mathrm{~cm}$ at a $95 \%$ confidence level. Actual VVA accuracy was found to be $\pm 9.87 \mathrm{~cm}$ at the 95 th percentile.

\subsection{A General Algorithm of the Case Study}

Depending on the methodology, a general algorithm of the study is prepared and showed as a table (Figure 19) [45]. 


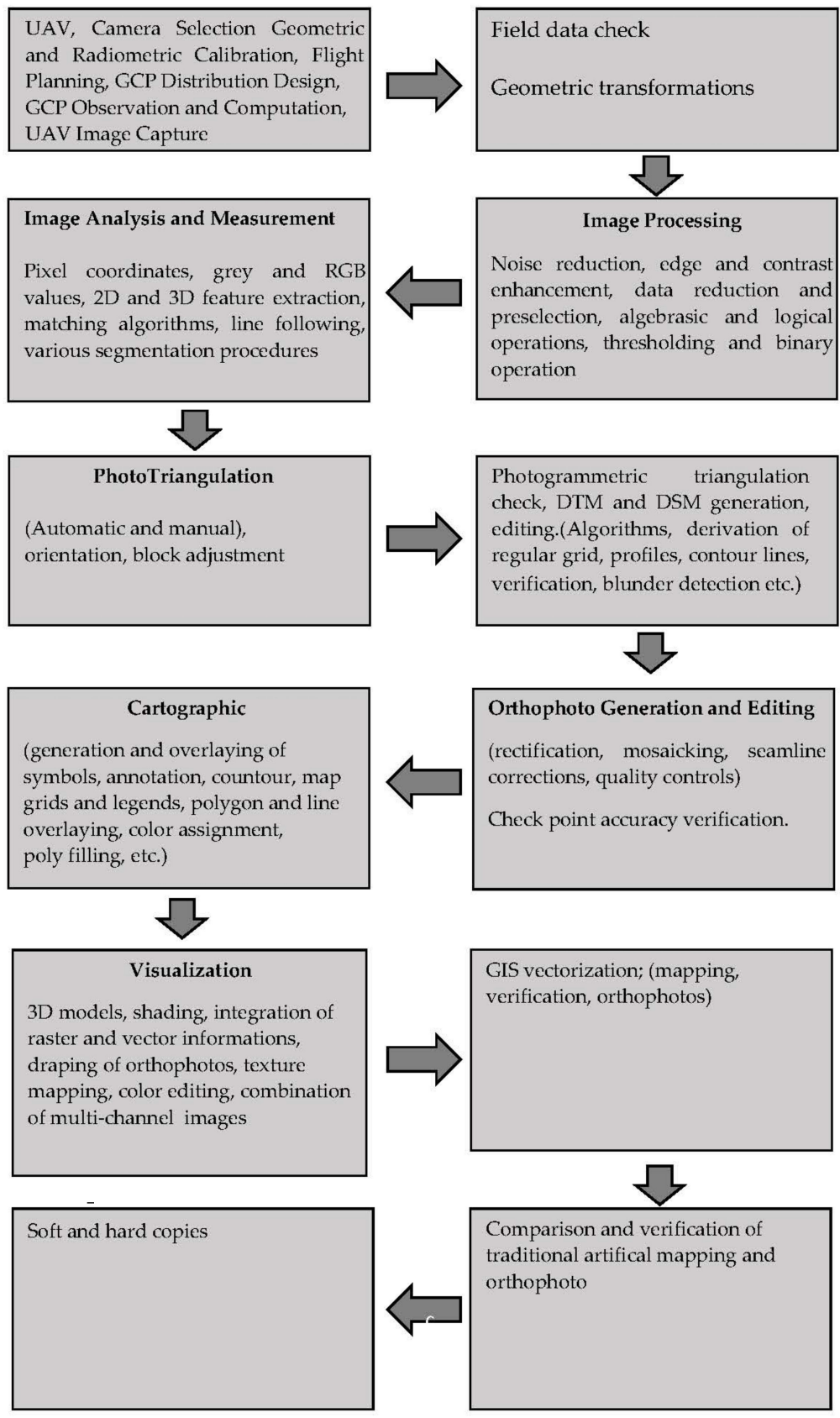

Figure 19. A general algorithm of the study (derived from Ref. [45]).

\section{Results}

Orthophoto has been used for many years in large-scale mapping and archaeological projects. With rapid development in technology, it has started to use digital orthophotos as a map since they are all corrected images. The ability of direct measurement in orthophotos has made them indispensable for complex heritage documentation such as large archaeological areas. For this reason, the factors affecting the accuracy of orthophoto should be considered in the production process.

The aim of this study was to check the positional accuracy of an orthophoto created by the images from a UAV and assess the positional accuracy of the orthophoto aiming for large-scale archaeological documentation. In this study, high-resolution aerial images of an archaeological area were collected with a fixed-wing UAV. Ground control points were established and measured using the RTK-GPS method. A high-resolution orthophoto was created. The horizontal and vertical positional accuracy of the orthophoto was evaluated 
mainly in terms of RMSE and checked according to the ASPRS. Both the horizontal and vertical accuracy results are at a 95\% confidence level. From the result obtained, UAVs could be used for large-scale mapping and documentation of large archaeological areas. In particular, even when the area is very large, the acquired accuracy level is extremely good and suitable for archaeological 2D drawings.

Author Contributions: In this research, Conceptualization, S.A.G.K. and F.Y.; methodology, F.Y.; software, S.A.G.K.; validation, S.A.G.K.; formal analysis, F.Y.; investigation, S.A.G.K.; resources, S.A.G.K.; data curation, S.A.G.K.; writing-original draft preparation, S.A.G.K.; writing-review and editing, F.Y.; visualization, S.A.G.K.; supervision, F.Y.; project administration, F.Y. All authors have read and agreed to the published version of the manuscript.

Funding: This research received no external funding.

Acknowledgments: The authors would like to thank Erkan Baygül from Paksoy Teknik Tic. Ltd. Şti. for his help and effort in technical support in material UAV system and field work.

Conflicts of Interest: The authors declare no conflict of interest.

\section{References}

1. Eisenbeiss, H. A Mini Unmanned Aerial Vehicle [UAV]: System Overview and Image Acquisiton. In Proceedings of the International Workshop on Processing and Visualization Using High-Resolution Imagery, Pitsanulok, Thailand, 18-20 November 2004.

2. Themistocleous, K. The use of UAVs to monitor archeological sites: The case study of Choirokoitia within the PROTHEGO project. In Proceedings of the Fifth International Conference on Remote Sensing and Geoinformation of the Environment [RSCy2017], Paphos, Cyprus, 20-23 March 2017; Volume 10444. [CrossRef]

3. Bendea, H.; Chiabrandao, F.; Giulio Tonolo, F.; Marenchino, D. Mapping of archaeological areas using with a low-cost UAV the Augusta Bagiennorum test site. Presented at the XXI International CIPA Symposium, Athens, Greece, 1-6 October 2007.

4. Remondino, F.; Barazzetti, L.; Nex, F.; Scaioni, M.; Sarazzi, D. UAV Photogrammetry for Mapping and 3D Modelling-Current Status and Future Perspectives. Presented at the ISPRS ICWG I/V-UAV-g [Unmanned Aerial Vehicle in Geomatics] Conference, Zurich, Switzerland, 14-16 September 2011.

5. Patias, P.; Grussenmeyer, P.; Hanke, K. Applications in Cultural Heritage Documentation. Presented at the XXIth ISPRS Congress: Silk Road for Information from Imagery, Beijing, China, 3-11 July 2008.

6. Cowley, D.C. Remote Sensing for Archaeological Heritage Management. Presented at the 11th EAC Heritage Management Symposium, Reykjavík, Iceland, 25-27 March 2010.

7. Lo Brutto, M.; Borruso, A.; D'Argenio, A. UAV systems for photogrammetric data acquisition of archaeological sites. In Proceedings of the EUROMED 2012: Progress in Cultural Heritage Preservation, Limassol, Cyprus, 29 October-3 November 2012; pp. 7-13.

8. Willis, M.D.; Koeing, C.W.; Black, S.L.; Castaneda, A.M. Archaeological 3D Mapping: The Structure from Motion Revolution. Index Tex. Archaeol. Open Access Gray Lit. Lone Star State 2016, 2016, 110.

9. Eisenbeiß, H. UAV Photogrammetry. Ph.D. Thesis, ETH Zurich, Zürich, Switzerland, 2009.

10. Mozas-Calvache, A.; Prez-Garca, J.; Cardenal-Escarcena, F; Mata-Castro, E.; Delgado-Garca, J. Method for Photogrammetric Surveying of Archaeological Sites with Light Aerial Platforms. J. Archaeol. Sci. 2012, 39, 521-530. [CrossRef]

11. Rinaudo, F.; Chiabrando, F.; Lingua, A.; Spanò, A. Archaeological Site Monitoring: UAV Photogrammetry can be an answer. Presented at the XXII ISPRS Congress, Melbourne, Australia, 25 August-1 September 2012.

12. Anuar, A.; Khairul, N.T.; Wani, S.U.; Khairil, A.H.; NorHadija, D.; Mohd, H.; Shahrul, M.A. Digital Aerial Imagery of Unmanned Aerial Vehicle for Various Applications. Presented at the IEEE International Conference on Control System, Computing and Engineering, Penang, Malaysia, 29 November-1 December 2013.

13. Sauerbier, M.; Eisenbeiss, H. UAV for the Documentation of Archaeological Excavations. Presented at the ISPRS 2010: Close Range Image Measurement Techniques, Newcastle upon Tyne, UK, 21-24 June 2010.

14. Skarlatos, D.; Theodoridou, S.; Glabenas, D. Archaeological Surveys in Greece Using Radio Controlled Helicopter. Presented at the FIG Working Week 2004, Athens, Greece, 2-27 May 2004.

15. Hendrickx, M.; Wouter Gheyle, W.; Bonne, J.; Bourgeois, J.; Wulf, A.; Goossens, R. The Use of Stereoscopic Images Taken from a Microdrone for the Documentation of heritage: An example from the Tuekta burial mounds in the Russian Altay. J. Archaeol. Sci. 2011, 38, 2968-2978. [CrossRef]

16. Eisenbeiss, H.; Lambers, K.; Sauerbier, M. Photogrammetric Recording of the Archaeological Site of Pinchango Alto [Palpa, Peru] Using a mini Helicopter [UAV]. Presented at the CAA 2005: The World Is in Your Eyes: CAA 2005: Computer Applications and Quantitative Methods in Archaeology, Tomar, Portugal, 21-24 March 2005.

17. Verhoeven, G.J.; Loenders, J.; Vermeulen, F.; Docter, R. Helikite aerial Photography or HAP-A versatile means of unmanned, radio controlled low altitude aerial archaeology. Archaeol. Prospect. 2009, 16, 125-138. [CrossRef]

18. Haubeck, K.; Prinz, T. UAV-Based Low-Cost Stereo Camera System for Archaeological Surveys-Experiences from Doliche [Turkey]. Presented at the UAV-g2013, Rostock, Germany, 4-6 September 2013. 
19. Mesas-Carrascosa, J.F.; Rumbao, C.I.; Berrocal, B.A.J.; Porras, F.-G.A. Positional Quality Assessment of Orthophotos Obtained from Sensors Onboard multi-Rotor UAV Platforms. Sensors 2014, 14, 22394-22407. [CrossRef]

20. Wemegah, D.T.; Amissah, B.M. Accuracy Checks in the Production of Orthophotos. J. Environ. Earth Sci. 2013, 3, 14-21.

21. Liu, Y.; Zheng, X.; Ai, G.; Zhang, Y.; Zuo, Y. Generating a High-Precision true Digital Orthophoto Map Based on UAV Images. ISPRS Int. J. Geo-Inf. 2018, 7, 333. [CrossRef]

22. Sai, S.S.; Tjahjadi, M.E.; Rokhmana, C.A. Geometric Accuracy Assessments of Orthophoto Production From UAV Aerial Images. In Proceedings of the 1st International Conference on Geodesy, Geomatics, and Land Administration 2019, Semarang, Indonesia, 24-25 July 2019; KnE Engineering: Semarang, Indonesia, 2019; pp. 333-344. [CrossRef]

23. Wolf, R.P.; Dewit, A.B.; Wilkinson, E.B. Elements of Photogrammetry: With Applications in GIS, 3rd ed.; McGraw-Hill Companies Inc.: New York, NY, USA, 2000; pp. 217-225.

24. United States Bureau of the Budget. United States National Map Accuracy Standards; Bureau of the Budget: Washington, DC, USA, 1947.

25. Federal Geographic Data Committee [FGDC]. Revision of Geospatial Positioning Accuracy Standards, Part 3. In National Standard for Spatial Data Accuracy; fgdc-std-007.3-1998; FGDC Standard Projects. Available online: http://www.Fgdc.Gov/standards/ projects/fgdc-standards-projects/accuracy/part3/nssda-revision-proposal (accessed on 26 December 2013).

26. Standardization Agreements. In S. Standardization Agreement 2215: Evaluation of Land Maps, Aeronautical Charts and Digital Topographic Data; North Atlantic Treaty Organization: Bruxelles, Belgium, 2002.

27. Greenfeld, J. Evaluating the Accuracy of Digital Orthophoto Quadrangles [DOQ] in the Context of Parcel-Based GIS. Photogramm. Eng. Remote Sens. 2001, 67, 199-206.

28. Hashim, K.A.; Darwin, N.H.; Ahmad, A.; Samad, A.M. Assessment of low altitude aerial data for large scale urban environmental mapping. In Proceedings of the 2013 IEEE 9th International Colloquium on Signal Processing and Its Applications [CSPA], Kuala Lumpur, Malaysia, 8-10 March 2013; pp. 229-234.

29. Tsarovski, S. Accuracy Evaluation and Quality Control of Digital Orthomap-Sheets. In Proceedings of the FIG Working Week 2015: From the Wisdom of the Ages to the Challenges of the Modern World, Sofia, Bulgaria, 17-21 May 2015.

30. Julge, K.; Ellmann, A. Evaluating The Accuracy of Orthophotos and 3D Models from UAV Photogrammetry. In Geophysical Research Abstracts, Proceedings of the EGU General Assembly, Vienna, Austria, 12-17 April 2015; European Geosciences Union: Munich, Germany, 2015; Volume 17, p. EGU2015-655.

31. Popescu, G.; Iordan, D.; Paunescu, V. The Resultant Positional Accuracy FOR THE Orthophotos obtained with Unmanned Aerial Vehicles [UAVs]. Sci. Agric. Agric. Sci. Procedia 2016, 10, 458-464. [CrossRef]

32. Baehr, H.-P. Appropriate Pixel Size for Orthophotography. In Proceedings of the 17th ISPRS Congress, Washington, DC, USA, 2-14 August 1992; Volume 29, pp. 64-72.

33. Kulur, S.; Yildiz, F.; Selcuk, O.; Yildiz, M.A. The Effect of Pixel Size on the Accuracy of Orthophoto Production. In Proceedings of the ISPRS Annals of the Photogrammetry, Remote Sensing and Spatial Information Sciences, XXIII ISPRS Congress, Prague, Czech Republic, 12-19 July 2016; Volume 3-4.

34. Kapnias, D.; Milenov, P.; Kay, S. Guidelines for Best Practice and Quality Checking of Ortho Imagery; Joint Research Centre: Ispra, Italy, 2008.

35. The American Society for Photogrammetry and Remote Sensing (ASPRS). Accuracy Standards for Digital Geospatial Data; ASPRS: Bethesda, MD, USA, 2013; Available online: www.asprs.org (accessed on 15 February 2018).

36. Udin, W.S.; Ahmad, A. Assessment of Photogrammetric Mapping Accuracy Based on Variation Flying Altitude Using Unmanned Aerial Vehicle. IOP Conf. Ser. Earth Environ. Sci. 2014, 18, 012027. [CrossRef]

37. Sisay, G.Z.; Besha, T.; Gessesse, B. Feature Orientation and Positional Accuracy Assessment of Digital Orthophoto and Line Map for Large Scale Mapping: The Case Stduy on Bahir Dar town, Ethiopia. In International Archives of the Photogrammetry, Remote Sensing and Spatial Information Sciences, Volume XLII-1/W1, Proceedings of the 2017 ISPRS Hannover Workshop: HRIGI 17-CMRT 17-ISA 17-EuroCOW 17, Hannover, Germany, 6-9 June 2017; International Society of Photogrammetry and Remote Sensing (ISPRS): Hannover, Germany, 2017.

38. Arık, R. Kubad Abad Selçuklu Sarayı ve Çinileri; Türkiye İş Bankası Kültür Yayınları: Istanbul, Turkey, 2000.

39. Daş, E. Kubadabad Palace. 2017. Available online: http:/ / www.discoverislamicart.org (accessed on 15 February 2018).

40. Available online: https://www.pusulahaber.com.tr/kubad-abad-sarayi-cinileriyle-goz-kamastiriyordu-7054yy.htm (accessed on 20 April 2021).

41. Nex, F.; Remondino, F. UAV for 3D Mapping Applications: A Review. Appl. Geomat. 2014, 6, 1-15. [CrossRef]

42. Xiang, H.; Tian, L. Development of a Low-Cost Agricultural Remote Sensing System Based on an Autonomous Unmanned Aerial Vehicle (UAV). Biosyst. Eng. 2011, 108, 174-190. [CrossRef]

43. Chiang, W.-K.; Tsai, L.-M.; Naser, S.E.; Habib, A.; Chu, H.-C. A New Calibration Method Using Low Cost MEM IMUs to Verify the Performance of UAV-Borne MMS Payloads. Sensors 2015, 15, 6560-6585. [CrossRef] [PubMed]

44. Rock, G.; Ries, J.B.; Udelhoven, T. Sensitivity Analysis of UAV-photogrammetry for creating digital elevation models (DEM). In International Archives of the Photogrammetry, Remote Sensing and Spatial Information Sciences, Vol. XXXVIII-1/C22 UAV-g 2011, Proceedings of the Conference on Unmanned Aerial Vehicle in Geomatics, Zurich, Switzerland, 14-16 September 2011; International Society of Photogrammetry and Remote Sensing (ISPRS): Hannover, Germany, 2011.

45. Baltsavias, E.P.; Gruen, A.; Meister, M. DOW-A System Generation of Digital Orthophotos from Aerial and Spot Images. EARSel Adv. Remote Sens. 1992, 1, 105-112. 